\title{
Fabrication of metallic and non-metallic top electrodes for large-area molecular junctions
}

\author{
Elena Gorenskaia ${ }^{1}$, Kelly L. Turner ${ }^{1}$, Santiago Martín ${ }^{2,3,4}$, Pilar Cea ${ }^{2,3,4}$, Paul J. Low ${ }^{1}$ \\ ${ }^{1}$ School of Molecular Sciences, University of Western Australia, 35 Stirling Highway, Crawley, WA, 6009, Australia. \\ ${ }^{2}$ Instituto de Nanociencia y Materiales de Aragón (INMA), CSIC-Universidad de Zaragoza, Zaragoza 50009, Spain. \\ ${ }^{3}$ Departamento de Química Física, Facultad de Ciencias, Universidad de Zaragoza, 50009, Zaragoza, Spain. \\ ${ }^{4}$ Laboratorio de Microscopias Avanzadas (LMA). Universidad de Zaragoza, Edificio I+D+i. 50018, Zaragoza, Spain.
}

\begin{abstract}
Molecular junctions have proven invaluable tools through which to explore the electronic properties of molecules and molecular monolayers. In seeking to develop a viable molecular electronics based technology it becomes essential to be able to reliably create larger area molecular junctions by contacting molecular monolayers to both bottom and top electrodes. The assembly of monolayers onto a conducting substrate by self-assembly, Langmuir-Blodgett and other methods is well established. However, the deposition of top-contact electrodes without film penetration or damage from the growing electrode material has proven problematic. This Review highlights the challenges of this area, and presents a selective overview of methods that have been used to solve these issues.
\end{abstract}

\section{General introduction}

A molecular junction consists of a molecule (or molecules), suitably functionalised to allow physical and electrical contact to solid substrates, sandwiched between two electrodes (Figure 1). ${ }^{1}$ The electrical transport through the molecule in response to a bias applied across the electrodes forms the basis of the field of molecular electronics. Beyond wire-like conductance through the molecule in response to the applied bias, the ability of the molecule to modulate the flow of current through the junction either through inherent asymmetries in structure or in response to mechanical, optical, photochemical, electrochemical or chemical processes has given rise to examples of molecular-scale electronic components including switches, transistors, memory elements, diodes, rectifiers, ${ }^{2}$ and single molecule light-emitting diodes. ${ }^{3}$ The discovery of quantum interference effects on electron transport through a molecular junction has given rise to new concepts for the chemical design of molecular electronic components, ${ }^{4,5}$ including remarkable 'better than vacuum' resistors. ${ }^{6}$ The quantum transport characteristics of molecular junctions may allow molecular materials to realise properties that are difficult to engineer in solid-state materials, such as the combination of high Seebeck coefficients and high electrical conductivity with low thermal conductivity necessary to create efficient thermoelectric materials. ${ }^{7,8}$ 


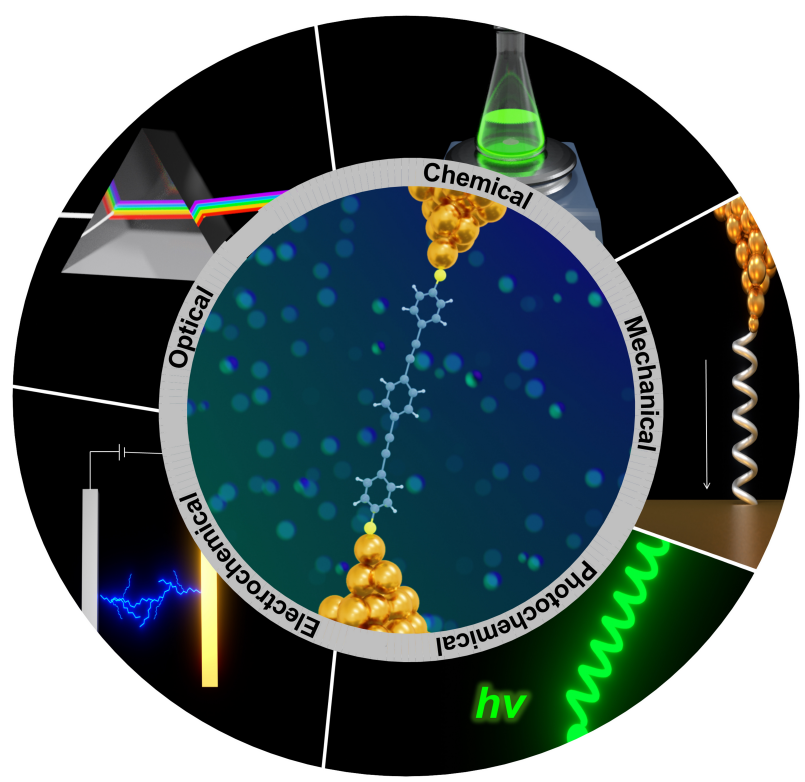

Figure 1 Schematic illustration of a single-molecule electrode |molecule|electrode junction.

Single-molecule junctions have proven to be remarkably versatile research tools in the field of molecular electronics. ${ }^{9,} 10$ Perhaps the most common approach to the formation of such singlemolecule devices is the use of a scanning tunnelling microscope to create a break junction (STM-BJ) (Figure 2). ${ }^{11}$ Whilst there are many variations of the technique, ${ }^{12}$ in the most general fashion an STM tip (typically gold) is crashed into a gold substrate to create a fused metal junction. The tip is subsequently withdrawn from the surface, pulling a metallic filament between the malleable gold surface and tip. As the tip continues to withdraw the filament thins, evinced by stepwise drops in quantised conductance, and ultimately breaks, leaving two atomically sharp 'electrodes', with a consequent sharp drop from metal-atom point contact conductance $\left(G_{0}\right)$ to the exponentially distance dependant tunneling current. If the experiment is conducted in a dilute solution of the molecule of interest, there is a possibility of trapping a molecule within the newly formed electrode gap to give the molecular junction (Figure 2). Other methods such as the 'in-plane' mechanically controlled break junction (MCBJ) offer advantages in terms of stability, ability to operate in vacuum or readily introduce a back-gate electrode ${ }^{13,14}$ but the basic principals are similar. Further in-plane techniques include electromigration break junctions, ${ }^{15,}{ }^{16}$ on-wire lithography, ${ }^{17}$ also in combination with in situ molecular synthesis between the electrode surfaces using chemical ${ }^{18}$ or biochemical ${ }^{19}$ approaches. 


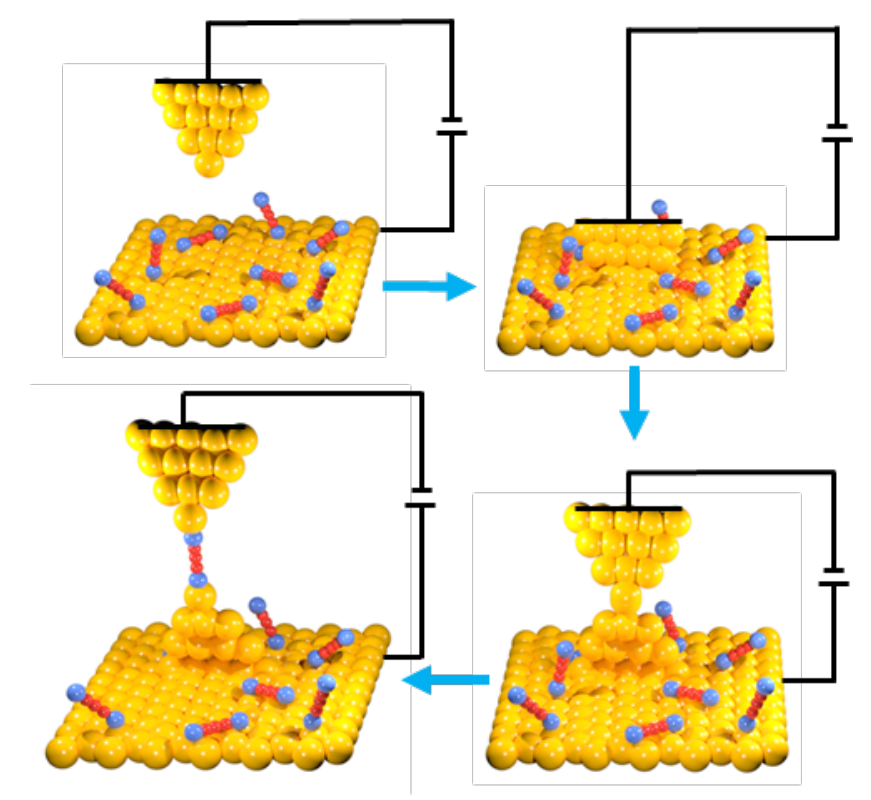

Figure $2 \mathrm{~A}$ cartoon showing the key features of single-molecule junction formation using the scanning tunelling microscope-break junction (STM-BJ) method.

The remarkable success of single-molecule junctions in driving the development of structureproperty relationships in molecular electronics should not overlook the origins of molecular junction studies and the important role that 'large area' junctions have played in developing the field. Almost a decade before the development of scanning probe microscopes at IBM by Binning and Rohrer in the late 1970 s and early $1980 \mathrm{~s}^{20}$ Mann and Kuhn had already explored the electrical characteristics of monolayers of fatty acid salts deposited on Al on glass substrates and contacted by a Hg drop or evaporated $\mathrm{Pb}$ or $\mathrm{Al}$ second electrode. ${ }^{21}$ The exponential relationship between the thickness of the monolayer and conductivity provided clear evidence for through molecule tunneling behaviour. The Donor-Acceptor structure and anisotropic arrangement of the Aviram-Ratner molecular rectifier within a junction presented in 1974 prompted a vast body of work exploiting the use of LangmuirBlodgett films and self-assembled monolayers in the construction of molecular rectifiers through the 1980 s and 1990s. ${ }^{22,23}$ Despite the remarkable success of these early works, the challenges associated with the fabrication of high-quality monolayers, and the vexing issues of installing the top-contact electrode has seen a shift in emphasis towards single molecule junctions as a tool for probing the fine-details of through-molecule charge transport phenomena.

Over the past 50 years, these studies of film-based and single-molecule junctions have combined to give a remarkable level of understanding concerning molecular electronic properties and structure-property relationships that control the electrical properties of junctions. However, in order to exploit molecular electronics as a viable technology, whether as components for advanced ultra-miniaturised high-performance electronics, as cheap components for disposable electronics, or novel molecular materials, the issues of how to contact molecules within circuit elements or practical device structures must be solved. Thus, whilst single-molecule junctions have proven to be extraordinary research tools, the translation from single-molecule science to a molecular electronic technology arguably requires a migration back towards junctions in which a uniform monolayer of molecules is reliably contacted between larger-area electrodes. ${ }^{24,}{ }^{25}$ There have already been tantalising glimpses of what is possible with such large-area and molecular-film based junctions, ranging from molecular memories featuring on redox-responsive rotaxanes in nanofabricated cross- 
bar architectures $^{26}$ molecular diodes in audio circuits, ${ }^{27}$ and molecular-junction based photosensors. ${ }^{28}$

Fabrication of large area devices implies first the deposition of a monolayer onto a bottomelectrode to form high-quality and reproducible assemblies (Figure 3). The formation of well-ordered molecular monolayers on conducting substrates is a well-established process by any one of a number of processes (self-assembly, Langmuir-Blodgett, vacuum deposition, electrografting, etc.) that allows the fabrication of modified electrodes with a surface density of up to $10^{15}$ molecules $\cdot \mathrm{cm}^{-}$ 2. As such the contacting of molecular films to the 'bottom' electrode is essentially a routine operation. The second step is the deposition of a top electrode onto the molecular monolayer that represents a more open research field due to many technical difficulties which include: deposition without destroying the organic monolayer, formation of pinholes and short-circuits, alteration or contamination of the interface, quality of the contacts, surface coverage of the top contact, etc. (Figure 3). Consequently, the creation of the top contact to the monolayer to complete the largearea junction has been proven to be a remarkably difficult undertaking. ${ }^{29}$
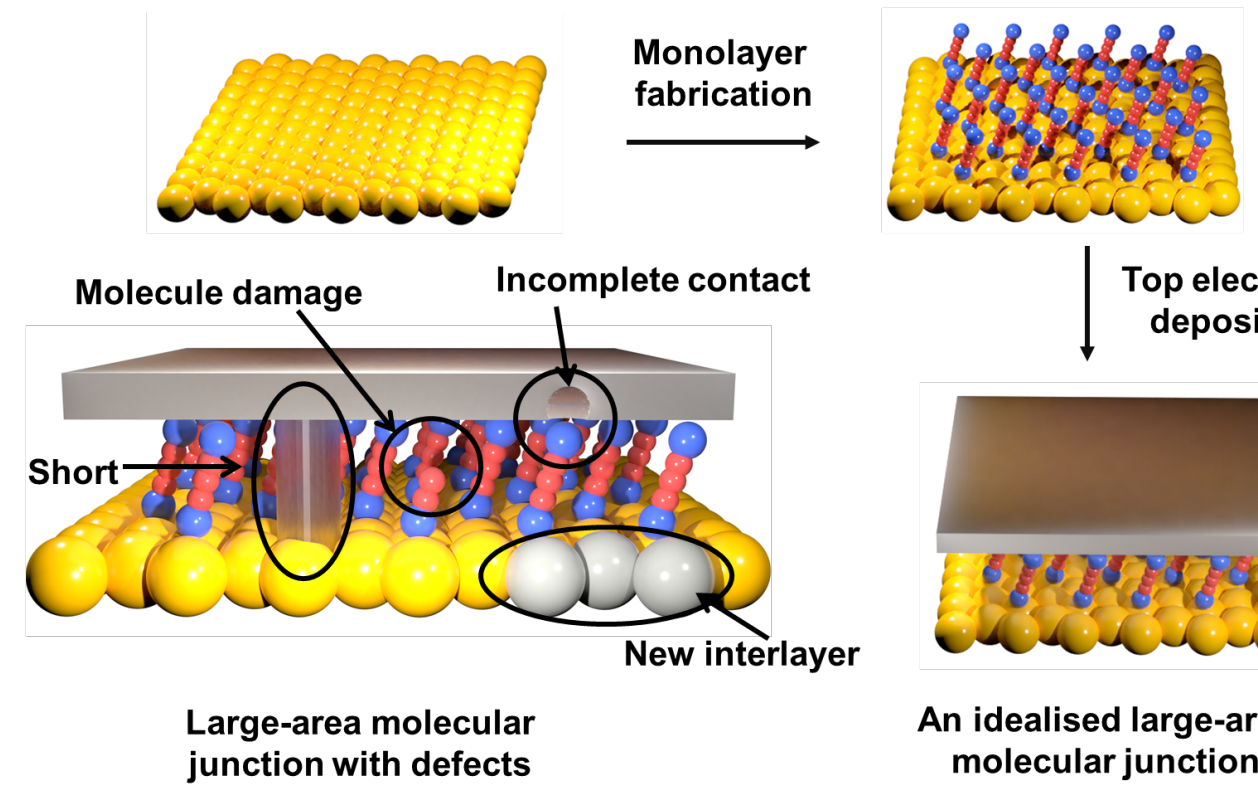

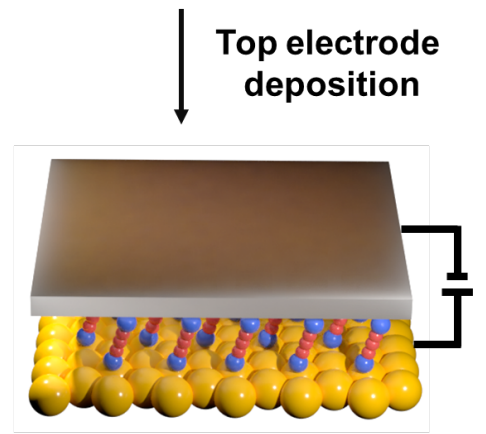

An idealised large-area molecular junction

Figure $3 \mathrm{~A}$ cartoon showing the idealised two steps involved in the fabrication of large area molecular junctions. The expansion illustrates possible defects and damage arising from top-contact deposition.

\section{Top-contact deposition strategies: An overview}

The idealised large-area metal|molecule/metal junction, and associated key issues in realising this arrangement, are summarised in Figure 3. To provide assessment of the electrical properties of molecules contained within the monolayer, scanning probe tips of varying radius of curvature can be used to make a top contact to one or many molecules (Section 2). Various strategies have been pursued to realise the idealised structure of a uniform molecular layer sandwiched between, and electrically well-contacted to, two larger area electrode surfaces. The use of liquid metals $(\mathrm{Hg})$ and 
eutectics $(\mathrm{Ga} / \mathrm{In})$ has been successfully demonstrated, although the suitability of liquid electrodes for device fabrication might be debated, and are discussed in Section 3. Incubation of suitably 'top surface' functionalised films with solutions of metallic nanoparticles leads to decoration of the film with particles, but not a complete metallised top contact. Similar structures have been obtained from the recently reported photoreduction of $\left[\mathrm{AuCl}_{4}\right]^{-}$adsorbed to the surface of an ammoniumterminated Langmuir-Blodgett film, and the thermally induced decomposition (reduction) of organometallic (gold (I)) complexes (TIDOC) with a sacrificial (oxidisable) co-ligand on a conjugated molecular monolayer. These metal islands may serve as seeds for further electroless infill to give a more continuous metallic top electrode (Section 4).

Various 'soft' deposition methods including nanotransfer printing and lift-off-float-on have been explored, but the electrical contact to the underlying molecular layer is often weak, and highly variable. Electrochemical deposition of metallic top contacts frequently leads to interpenetration as reducible metal ions migrate through the organic film giving mushroom-shaped structures or shorts as growing metallic filaments contact the bottom electrode. Atomic layer deposition (ALD) is a promising route, although the surface chemistry between the mono-layer and the ALD precursor and the subsequent reduction chemistry needs to be more fully explored to better understand the processes. Perhaps the simplest route is direct thermal evaporation of a metal onto the monolayer. However, here the high energy of the evaporated metal atoms often results in significant film damage, interpenetration and formation of metallic shorts, or migration of metal atoms through the film at static pinholes or through transient diffusion channels form new interlayers and alloys at the bottom electrode.

In seeking to overcome these issues, the use of various protective barrier layers on top of the monolayer have been explored, with particular promising results being obtained following spincoating of a poly(3,4-ethylenedioxythiophene):poly(4-styrenesulphonic acid) (PEDOT:PSS) conductive polymer on top of an alkane dithiol monolayer prior to vapour deposition of a gold top electrode. However, this again results in the introduction of a series of gold:polymer:monolayer interfaces, each with their own electrical characteristics. Similar ideas relating to the blocking of the diffusion channels that lead to metal penetration through the monolayer have been explored by cross-linking the monolayer, although again this results in a change in the chemical structure of the molecules comprising the monolayer. Other approaches that have met with a degree of success include the introduction of functional groups capable of interacting with the metal atoms near the monolayer surface to limit migration of metal atoms through the monolayer. These various areas are discussed in Section 5.

In this Review, we seek to present a series of highlights drawn from various approaches taken to solve the 'top-contact problem' in order to allow the reader to develop an appreciation of the main concepts and methods of forming large-area molecular electronic junctions. In doing so we hope to raise awareness of new opportunities for the creation of nanosized electronic device structures with desirable characteristics. 
Table 1. Summary table of top-contact deposition methods.

\begin{tabular}{|c|c|c|c|}
\hline Method & Common Materials & Advantages & Disadvantages \\
\hline Liquid top-electrodes & $\mathrm{Hg}$, EGaln & $\begin{array}{l}\text { Soft and cost effective } \\
\text { method; Multiple and } \\
\text { repeated } \\
\text { measurements on the } \\
\text { same device structure } \\
\text { are unproblematic. }\end{array}$ & $\begin{array}{l}\text { Difficult to incorporate } \\
\text { into permanent device } \\
\text { structures; Fluidity of } \\
\text { liquid metal contacts } \\
\text { limits miniaturization; } \\
\text { Temperature } \\
\text { dependent changes in } \\
\text { volume. }\end{array}$ \\
\hline $\begin{array}{l}\text { Self-assembly of metal } \\
\text { nanoparticles onto the } \\
\text { underlying monolayer }\end{array}$ & $\mathrm{Au}, \mathrm{Ag}, \mathrm{Pd}$ & $\begin{array}{l}\text { Soft method; } \\
\text { Metallic nanoparticles } \\
\text { can be used as top- } \\
\text { contact directly, or } \\
\text { used as seeds for ELD } \\
\text { or as buffers to protect } \\
\text { the monolayer during } \\
\text { vapour deposition to } \\
\text { increase metallization. }\end{array}$ & $\begin{array}{l}\text { Incomplete } \\
\text { metallization; Diffusion } \\
\text { on the surface and } \\
\text { potential aggregation } \\
\text { of the nanoparticles } \\
\text { upon temperature } \\
\text { changes giving } \\
\text { inhomogeous contacts. }\end{array}$ \\
\hline $\begin{array}{l}\text { Physical vapour } \\
\text { deposition (PVD) }\end{array}$ & $\mathrm{Ti}, \mathrm{Ca}, \mathrm{Al}$ & $\begin{array}{l}\text { Relatively simple; } \\
\text { Wide range of } \\
\text { elements or } \\
\text { compounds can be } \\
\text { deposited. }\end{array}$ & $\begin{array}{l}\text { Metal atoms reach the } \\
\text { monolayer surface } \\
\text { with high kinetic } \\
\text { energy during } \\
\text { deposition that can } \\
\text { lead to chemical } \\
\text { modification of } \\
\text { monolayer surface; } \\
\text { Penetration of the } \\
\text { high-energy metal } \\
\text { atoms through } \\
\text { monolayers and } \\
\text { formation of metallic } \\
\text { filaments that can } \\
\text { result in short-circuits. }\end{array}$ \\
\hline $\begin{array}{l}\text { Chemical vapour } \\
\text { deposition (CVD) }\end{array}$ & $\mathrm{Al}_{\mathrm{x}} \mathrm{O}_{\mathrm{y}} \mathrm{H}_{\mathrm{z}}, \mathrm{Au}, \mathrm{Pd}, \mathrm{Pt}$ & $\begin{array}{l}\text { Suitable for deposition } \\
\text { of a wide variety of } \\
\text { materials. }\end{array}$ & $\begin{array}{l}\text { Damage of the } \\
\text { monolayer and } \\
\text { penetration of metal } \\
\text { atoms through the } \\
\text { monolayer resulting in } \\
\text { short-circuits; Slow } \\
\text { growth rates unless } \\
\text { high thermal activation } \\
\text { temperatures ( } \geq 200 \\
{ }^{\circ} \mathrm{C} \text { ) or additional } \\
\text { photochemical } \\
\text { methods are employed }\end{array}$ \\
\hline $\begin{array}{l}\text { Focused electron beam } \\
\text { induced deposition } \\
\text { (FEBID) }\end{array}$ & C & $\begin{array}{l}\text { High stability of } \\
\text { junctions; } \\
\text { Good reproducibility; }\end{array}$ & $\begin{array}{l}\text { Expensive } \\
\text { instrumentation; } \\
\text { Deposition may cause }\end{array}$ \\
\hline
\end{tabular}




\begin{tabular}{|c|c|c|c|}
\hline & & $\begin{array}{l}\text { Well-defined location, } \\
\text { shape, and size of } \\
\text { deposited top-contact. }\end{array}$ & $\begin{array}{l}\text { damage to } \\
\text { monolayers. }\end{array}$ \\
\hline $\begin{array}{l}\text { Surface-diffusion- } \\
\text { mediated deposition } \\
\text { (SDMD) }\end{array}$ & $\mathrm{Au}, \mathrm{Pt}, \mathrm{Cu}$ & $\begin{array}{l}\text { Good yield and } \\
\text { reproducibility; } \\
\text { Metal is not directly } \\
\text { evaporated onto } \\
\text { monolayers, which } \\
\text { helps to avoid damage } \\
\text { and penetration. }\end{array}$ & $\begin{array}{l}\text { Limited control over } \\
\text { the precise size and } \\
\text { location of the } \\
\text { deposition. }\end{array}$ \\
\hline $\begin{array}{l}\text { Atomic layer } \\
\text { deposition (ALD) }\end{array}$ & $\mathrm{Al}_{2} \mathrm{O}_{3}, \mathrm{Cu}$ & $\begin{array}{l}\text { Relatively gentle } \\
\text { atomic precision } \\
\text { deposition; } \\
\text { Provides high-quality } \\
\text { films cost effectively; } \\
\text { Pinhole-free } \\
\text { deposition. }\end{array}$ & $\begin{array}{l}\text { Requires monolayer } \\
\text { functionalised with } \\
\text { chemically specific } \\
\text { terminal groups; } \\
\text { Deposition can cause } \\
\text { film damage, } \\
\text { interpenetration, and } \\
\text { short circuits; Unclear } \\
\text { structure and } \\
\text { composition of the } \\
\text { interfaces. }\end{array}$ \\
\hline $\begin{array}{l}\text { Overpotential } \\
\text { deposition (OPD }\end{array}$ & $\mathrm{Cu}$ & $\begin{array}{l}\text { Electrochemical } \\
\text { procedure that does } \\
\text { not require the use of } \\
\text { expensive vacuum } \\
\text { equipment; } \\
\text { Easy to control top- } \\
\text { contact thickness. }\end{array}$ & $\begin{array}{l}\text { Clusters and metallic } \\
\text { filaments formation; } \\
\text { Incomplete } \\
\text { metallization. }\end{array}$ \\
\hline $\begin{array}{l}\text { Underpotential } \\
\text { deposition (UPD) }\end{array}$ & $\mathrm{Cu}, \mathrm{Ag}, \mathrm{Pd}, \mathrm{Al}$ & $\begin{array}{l}\text { Electrochemical } \\
\text { procedure that does } \\
\text { not require the use of } \\
\text { expensive vacuum } \\
\text { equipment; } \\
\text { Easy to control top- } \\
\text { contact thickness }\end{array}$ & $\begin{array}{l}\text { Clusters and metallic } \\
\text { filaments formation; } \\
\text { Not a homogeneous } \\
\text { metal layer; } \\
\text { Formation of an } \\
\text { interlayer; } \\
\text { Incomplete } \\
\text { metallization }\end{array}$ \\
\hline $\begin{array}{l}\text { Electroless deposition } \\
\text { (ELD) }\end{array}$ & $\mathrm{Cu}$ & $\begin{array}{l}\text { Simple, cost effective, } \\
\text { and soft; No } \\
\text { penetration of metal } \\
\text { through the monolayer; } \\
\text { Solution-based } \\
\text { technique that does } \\
\text { not require vacuum } \\
\text { equipment; Deposition } \\
\text { of metals and other } \\
\text { materials on a variety } \\
\text { of substrates; } \\
\text { Compatible with } \\
\text { insulating or low } \\
\text { conductivity materials. }\end{array}$ & $\begin{array}{l}\text { Extreme } \mathrm{pH} \text { conditions } \\
\text { that can damage } \\
\text { monolayers; Co- } \\
\text { deposition of residual } \\
\text { material and by- } \\
\text { products; Use of } \\
\text { catalysts that may } \\
\text { contaminate the organic } \\
\text { layer. }\end{array}$ \\
\hline Nanotransfer printing & $\mathrm{Au}$ & Soft method & Sensitivity to the \\
\hline
\end{tabular}




\begin{tabular}{|l|l|l|l|}
\hline (nTP) & & & $\begin{array}{l}\text { chemical nature of } \\
\text { terminal groups on the } \\
\text { monolayer. }\end{array}$ \\
\hline Lift-off, float-on (LOFO) & Au, Al & $\begin{array}{l}\text { Does not result in } \\
\text { penetration of top } \\
\text { contact through the } \\
\text { monolayer; Does not } \\
\text { rely on chemical binding } \\
\text { of molecules to top } \\
\text { contact electrodes. }\end{array}$ & $\begin{array}{l}\text { The wrinkling of metallic } \\
\text { layers; Air gaps between } \\
\text { monolayers and metallic } \\
\text { layers. }\end{array}$ \\
\hline $\begin{array}{l}\text { Polymer-assisted lift- } \\
\text { off (PALO) }\end{array}$ & $\mathrm{Au}$ & $\begin{array}{l}\text { High quality metal film; } \\
\text { Non damaging } \\
\text { deposition; Parallel } \\
\text { device fabrication. }\end{array}$ & $\begin{array}{l}\text { Difficult to align top } \\
\text { and bottom contacts } \\
\text { without using cross- } \\
\text { bar geometries. }\end{array}$ \\
\hline
\end{tabular}

\section{STM and AFM tips as temporal top contact electrodes}

The introduction of scanning probe techniques (SPM) played an essential role in the field of molecular electronics and created vast opportunities to fabricate top-contacts in both singlemolecule and large area molecular junctions. ${ }^{30}$ In a vertical junction with typical bottom electrode I monolayer | top electrode structure, an STM or conductive AFM tip plays a role of a temporal (and the smallest possible) top electrode thus making a junction with multiple numbers of molecules from one to hundreds dependent on the size of the tip and molecules as well as density of a monolayer (Figure 4). ${ }^{24}$ Despite the fact that systems with a temporal top electrode are far from technological applications, molecular junctions with SPM-based top contacts have proven essential in the search for fundamental understanding of electron transport properties of molecules and charge transport mechanisms. A key aspect of these studies arises from the possibility to more directly compare single-molecule and monolayer based junctions and thereby explore the influence of near neighbour interactions and the effects of the local environment on the electrical properties of the junction. ${ }^{31-34}$ In contrast, the inherent averaging of electrical transport over many molecules contacted under a larger tip can be used to give a more reasonable estimate of large area device performance free of the substantial statistical variation associated with single-molecule measurements. ${ }^{35}$ Moreover, the resistance variations for multimolecule junctions are smaller than for single molecule junctions, suggesting that large contact area with an increased number of molecules may be able to result in excellent reproducibility in nanodevice fabrication. ${ }^{35}$ STM conductance measurements in monolayers permit the study of a single molecule from this monolayer by contacting an atomically sharp tip to the molecule in the film. Although this review focuses on large-area junction formations, several studies in which the STM tip is in contact with only one molecule from the monolayer are also discussed here to give a wider appreciation of the scope of the technique. 


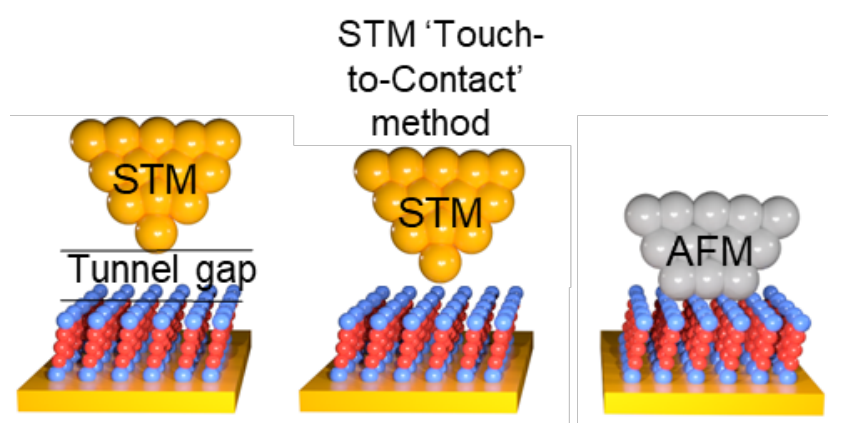

Figure 4 A schematic illustrating conventional STM, STM 'Touch-to-Contact' and (contact-mode) AFM tip-based top-contact electrodes to a molecular monolayer.

One of the difficulties in using a SPM tip as the top contact to a monolayer film junction is the precise determination of the relative position of the SPM tip and the monolayer, which is determined by the set-point current (Figure 4). If the tip is not in close proximity to the monolayer surface, the large tunnel gap can result in anomalously low conductance values, and given the exponential relationship between distance and tunneling current, sample to sample variation can be extreme without careful control over the set-point. On the other hand, using a too high set-point can result in penetration of the tip into the monolayer, distorting the film structure and giving rise to non-idealised junction geometries. A 'Touch-to-Contact' method has been suggested for such measurements, where the tip-substrate distance is determined through transforming the set-point parameters into an absolute gap separation allowing the STM tip to precisely contact the top of the molecular monolayer, ${ }^{36}$ minimizing the gap between the top of the monolayer and the tip yet avoiding incursion of the tip into a molecular monolayer.

The STM 'Touch-to-Contact' method has been used to form junctions and explore the electrical properties of a wide range of different molecular backbones assembled in monolayers including organic ${ }^{37-39}$ and organometallic ${ }^{36}$ examples, and with different binding groups. ${ }^{40-42}$ The sensitivity of molecular conductance measurements to the nature of the molecule-electrode contact is well known and arises from a combination of molecular geometry within the junction and the electrical coupling. ${ }^{43,44}$ Perhaps unsurprisingly therefore, it has been demonstrated that molecules with bidentate anchor groups are more conductive than monodentate analogues with the same molecular backbone. For example, the gold STM tip has been used as a top contact electrode to create junctions with an Langmuir-Blodgett (LB) monolayer of 4,4'-(1,4-phenylenebis(ethyne-2,1diyl))bis(pyridin-2-amine) (Figure 5a). ${ }^{32}$ The molecular conductance of the monolayer formed from this oligo(phenylene ethynylene) (or OPE) derivative that contains a double anchoring 2aminopyridine group was approximately an order of magnitude higher than OPE-based compounds with amine or pyridine contacts. Similarly, deprotonation of a pyrazolyl anchor group provided a more effective 'bidentate' NN contact than the native heterocycle, and a further increase in molecular conductance over the 2 -amino pyridine anchors (Figure $5 \mathrm{~b}$ ). ${ }^{45}$ In tripodal oligo(arylene)ethynylene derivatives two buttressing methylthioether groups provide additional strong S-Au interactions, enhancing the physical contact between the pyridyl groups and the electrode surface (Figure $5 c$ ). ${ }^{37}$ The buttressing groups were designed to be electrically decoupled from the molecular core by the methylene linker avoiding the quantum interference effect, and played little role in conductance pathways. 

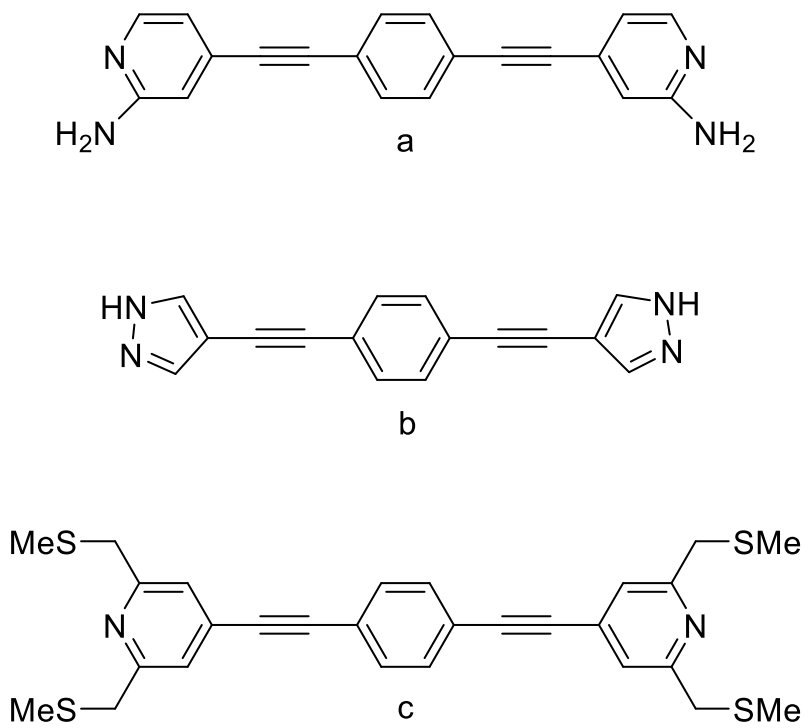

Fig 5. Selected examples of compounds used to investigate molecular conductivity in 'multi anchoring' molecules.

Conductive atomic force microscopy (C-AFM) is the other essential technique to investigate electron transport properties of molecules assembled into films and has been used to explore a wide range of molecular structure types ${ }^{46-48}$ and contacting strategies. ${ }^{49}$ C-AFM employs a sharp metalcoated conductive probe that also plays the role of a temporal top electrode (Figure 4). ${ }^{24,50,51}$ However, whilst sharp, the size of the C-AFM tip coated with a metallic layer is larger than the atomically sharp STM tip (radius of curvature) and usually forms junctions with tens to hundreds of molecules depending on the tip geometry, applied force, and deformation properties of the monolayer. The main distinguishing point of AFM from STM is that the position of the tip is controlled by force feedback rather than the current feedback. When the current-voltage characteristics are recorded in the C-AFM measurement, the loading force of the tip is controlled by the AFM feedback loop. This allows AFM tip to be in direct contact with the target material and to avoid the penetration of the tip into the monolayer, as well as offering a tool through which to investigate electrical and mechanical properties of the junctions concomitantly. Furthermore, as with the STM 'Touch-to-Contact' method, the direct contact of the AFM tip with the monolayer avoids the unknown contribution of the tunnelling gap to the detected current.

In principle, as the C-AFM method allows accurate control of the tip-loading force it becomes possible to investigate dependency of charge transport through a molecular junction on force applied to the monolayer. ${ }^{52-54}$ The influence of this contact force becomes apparent when the two contributions to the charge transport through self-assembled monolayers (SAMs) are each considered: (i) through-bond tunnelling where a current flows along the backbone, and (ii) chain-tochain tunnelling caused by intermolecular coupling through van der Waals (vdW) interactions. ${ }^{53}$ While the first mechanism is not affected by the tilt angle of the molecules within the monolayer, the chain-to-chain tunnelling is highly dependent on the precise intermolecular arrangement. As the molecular tilt increases with the tip-loading force, intermolecular interactions become significant leading to an increase in contribution from the chain-to-chain tunnelling to the overall junction conductance (Figure 6). Different tilt angles of molecules and, as a result, different electrical properties within the C-AFM junction can be caused not only by an applied force from the top electrode but also by polymorphism of the monolayer structure. For example, Paradinas et al. 
assessed the phase dependent conductivity of $\omega$-(4'-methylbiphenyl-4-yl)butane-1-thiol monolayers with two different phases by C-AFM. ${ }^{55}$ Using different surface science techniques it was found that rectangular centred $\alpha$-phase has a molecular tilt angle of $40^{\circ}$ while oblique $\beta$-phase has modestly larger tilt angle of $45-49^{\circ}$. The resistance value estimated from the linear low bias region was found to be $10^{2} \mathrm{G} \Omega$ and $10^{3} \mathrm{G} \Omega$ for $\beta$ and $\alpha$, respectively, which clearly demonstrates the impact of monolayer arrangement on electrical properties. Since the orientation of molecules in a monolayer as well as the presence of neighbouring molecules affects the electrical properties the use of binding groups that preference only one configuration of the molecules in the monolayer become appealing targets for study. A Pt/Cr C-AFM tip has been used as a top electrode to investigate triazatriangulenium (TATA) as a binding group for tunnel junctions of molecular wires on gold substrate surfaces. ${ }^{56}$ The large size of TATA provides both a normal orientation of a molecule to the substrate as well as preventing contact between molecules in a monolayer and thereby eliminating the chain-to-chain transport. It was found that phenyl-, biphenyl-, and terphenyl-TATAs demonstrated resistance that is only slightly higher than analogues with thiol and bis-thiol binding groups.

a

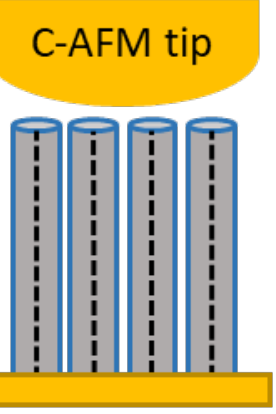

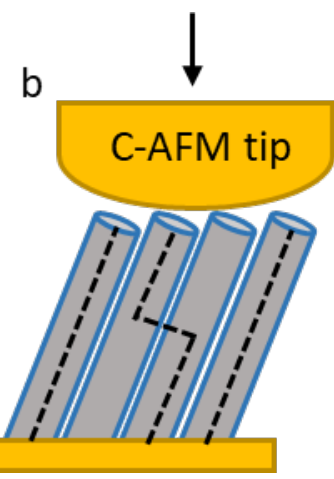

Figure 6 Schematic illustration of (a) through-bond tunnelling pathway, and (b) chain-to-chain tunnelling caused by an applied tip-loading force.

Within the context of these contact mode methods of forming the top contact to a monolayer, it is worth mentioning the Peak Force Tunneling (PF-TUNA) variation of C-AFM. Typically, C-AFM operates in contact mode with the tip brought to a close contact with the monolayer. Whilst the avoidance of a tunnel gap and ability to modulate tip-loading force has advantage as discussed above, this close contact can cause scratches and damage to the delicate monolayer surface. In the PF-TUNA mode, the tip is oscillated at a frequency typically between $100-500 \mathrm{kHz}$, with an amplitude of approximately $20 \mathrm{~nm}$, so that the tip is just touching the surface avoiding lateral forces that make this mode less damaging for the tip and the monolayer. This approach was successfully used to assess electrical properties in metal | monolayer |tip junctions, ${ }^{57}$ and also metal | monolayer | NP | tip junctions, ${ }^{58-60}$ where the AFM tip contacts metal nanoparticles (NP) at the top of the film rather than the monolayer itself. The use of GNPs as a top contact electrode is further discussed in Section 4. 


\section{Liquid metals top contact}

Liquid top-electrodes are an inexpensive and practical way to achieve soft surface contact with a SAM in a molecular junction. ${ }^{61-63}$ Ideally, a liquid top-electrode will i) have a sub-millimetre contact area with the SAM, ii) provide conformal, non-damaging and reversible contact, iii) disfavour amalgamation with the bottom electrode and iv) be non-toxic and simple to fabricate. ${ }^{64}$ To ensure uniform contact, liquid top-electrodes are best used with ultra-flat substrates, such as templatestripped coinage metals, ${ }^{65,66}$ silicon ${ }^{61}$ or graphene ${ }^{67}$ Initial devices to employ a liquid top-electrode used mercury to circumvent the need for metal vapour deposition, but there is a tendency to cause short junctions by damaging the underlying SAM. ${ }^{21}$ Nevertheless, by using a syringe and a micromanipulator, a mercury drop can be positioned on a surface, making electrical contact through a van der Waals interface. ${ }^{68}$ For mercury, the geometric area of this contact is in the order of millimetres and there are many successful molecular junction experiments using a mercury topelectrode. However, this contact area is relatively large, so may cover defects in the SAM, which will affect the measured electrical properties of the junction. Further, mercury is toxic, can penetrate the SAM causing short junctions and has a propensity to form alloys with other metals. ${ }^{69,} 70$ For these reasons, alternative liquid top-electrodes have been developed.

The most common modern liquid top-electrode is a eutectic mixture of indium ( $25 \mathrm{w} \%$ ) and gallium (75 w\%). This material, commonly denoted "EGaln" (pronounced "e-gain"), is a metallic nonNewtonian liquid under ambient conditions with a conductivity of $3.4 \times 10^{4} \mathrm{~S} \mathrm{~cm}^{-1}$. 64 Unlike mercury, EGaln has geometric contact areas as small as $<50 \mu \mathrm{m},{ }^{67}$ is biocompatible, and can form noninvasive and reversible contact in molecular junctions. ${ }^{64}$ Its non-Newtonian behaviour is attributed to a $0.7 \mathrm{~nm}$ thick gallium oxide $\left(\mathrm{Ga}_{2} \mathrm{O}_{3}\right)$ skin on its surface, which causes EGaln to be mouldable into shapes such as cones and filaments as small as $1 \mu \mathrm{m}$ in diameter (Figure 7)..$^{64,71}$

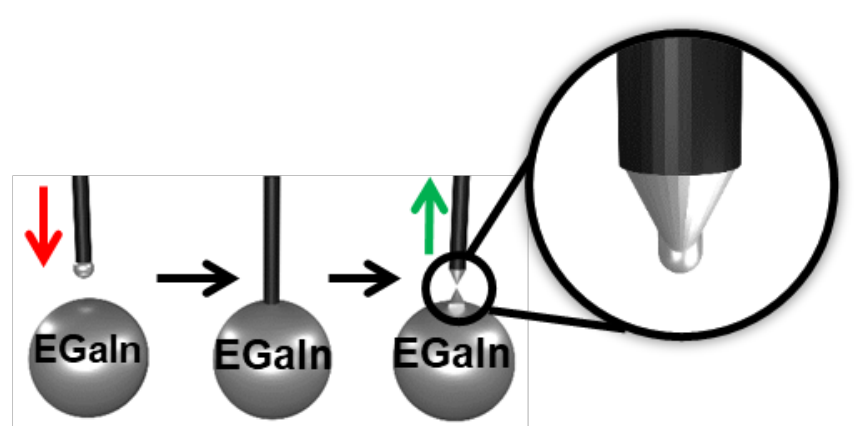

Figure 7 Formation of an EGaln tip by contacting and pulling from a bulk drop of this non-Newtonian fluid.

EGaln top-electrodes are often referred to as " $\mathrm{GaO}_{\mathrm{x}} / \mathrm{EGaIn"}$ to incorporate the gallium oxide skin. ${ }^{72}$ This oxide layer is highly conductive as it contains oxygen vacancies and indium defects, and is thin enough for a current to tunnel though it from the EGaln core. ${ }^{72}$ Nijhuis and co-workers have found that this skin can grow considerably thick ( $>2 \mathrm{~nm}$ ) when a bias of more than $+1.0 \mathrm{~V}$ is applied in the presence of water and ions. ${ }^{71}$ Crivillers has attributed this growth to the generation of a Mott potential between the oxide-air and oxide-EGaln interface when a tunnelling current through the oxide skin reduces adsorbed oxygen. ${ }^{67}$ This Mott potential drives ions through the skin, promoting oxidation and consequent growth. Under normal conditions, however, the oxide layer is 
shown to have little impact on electrical measurements of molecular junctions. ${ }^{73}$ Whitesides reported that the contribution of $\mathrm{Ga}_{2} \mathrm{O}_{3}$ on the current density through a molecular junction is constant between an EGaln electrode kept under nitrogen gas and one with a prolonged exposure to air. ${ }^{64}$ Many studies have since corroborated this conclusion. ${ }^{74}$

An advantage of EGaln as a top-electrode is its ability to form stable molecular junctions for periods long enough to collect statistically significant data sets ( $>400$ data). ${ }^{75}$ A study by Nijhuis and colleagues has shown that EGaln-SAM junctions can withstand more than $100 \mathrm{~J}(\mathrm{~V})$ scans at a bias of $\pm 0.1 \mathrm{~V}$ for $16 \mathrm{hr}^{71}$ It also produces high working junction yields of $80 \%-100 \%$ and is sensitive enough to conduct detailed physical-organic analyses. ${ }^{76}$ However, the precision and reproducibility of measurements performed with an EGaln top-electrode have been brought into question because i) the gallium oxide skin causes a surface roughness which affects the true contact area ${ }^{77}$ and ii) many EGaln top-electrodes are manipulated manually which imparts significant human error. ${ }^{75}$ Using a decanethiolate SAM on template-stripped gold and a conical EGaln top-electrode, Whitesides measured current density though the junction as a function of geometric contact area of the EGaln electrode. ${ }^{78}$ At contact areas less than $1000 \mu \mathrm{m}^{2}$, it was found that the current density increases with contact area but then plateaus from $1000 \mathrm{\mu m}^{2}$ up to $4000 \mu \mathrm{m}^{2}$. An EGaln cone has a rough tip and smooth sides such that, at small geometric contact areas, the rough tip has a large contribution to the measurement (Figure 8). At larger areas, this contribution diminishes as the smooth sides start to contact the surface. ${ }^{78}$ A similar conclusion was drawn by Yoon, whereby the Seebeck coefficient of a thermoelectric molecular junction was found to depend upon the tip roughness of a conical EGaln top-electrode. ${ }^{76}$ This means that small area measurements tend to be quite irreproducible as the true contact area is variable depending on tip roughness. However, small contact areas are needed to avoid defects in the SAM. ${ }^{79}, 80$ For this reason, Whitesides developed a method to smooth the EGaln tip by moulding it against a clean $\mathrm{Si} / \mathrm{SiO}_{2}$ surface and cycling an applied bias 3 times at $\pm 0.2 \vee{ }^{81}$ Crivillers also found that the tip roughness was lessened in an oxygen atmosphere. ${ }^{67}$ While these methods improved the reproducibility for a single data set, they do not address the discrepancies between different users. To tackle this, several authors have reported the use of a PDMS microfluidic device instead of a micromanipulator. In a microfluidic device, the EGaln is moulded into microchannels which has a stabilising effect and removes the manual element from the regime, significantly reducing human error between different users. ${ }^{72,82,83}$

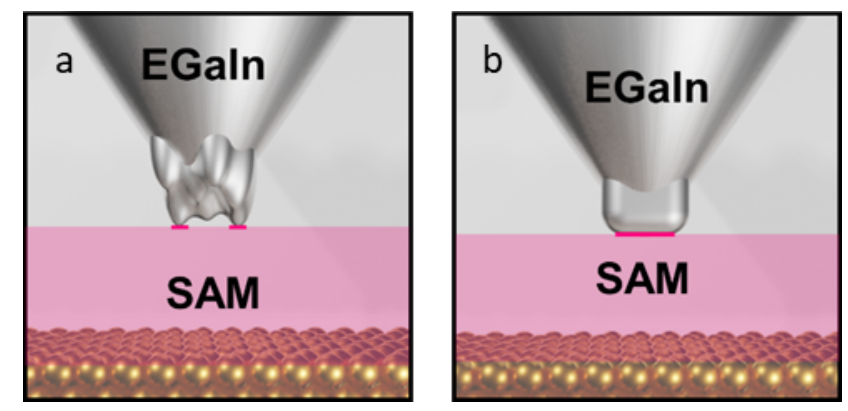

Figure 8 (a) Conical EGaln electrode with a rough tip and smooth sides. (b) A smoothed conical EGaln electrode with a well-defined contact area compared with the rough tip.

In 2012, Whitesides and Nijhuis set about proving that using EGaln, with its oxidisable and resistive $\mathrm{Ga}_{2} \mathrm{O}_{3}$ skin, in an asymmetrical electrode system did not cause rectification in an electrode- 
SAM-electrode regime.$^{84}$ Instead, only the SAM is thought to rectify current through the junction. Using a silver bottom electrode and an EGaln top electrode, they systematically varied the structure of a ferrocene-terminated SAM ( $\left.\mathrm{HS}-\left(\mathrm{CH}_{2}\right)_{11}-\mathrm{Fc}\right)$ to assess its effect on the current rectification performance of the junction (Figure 9). Despite its irreproducibility, they use a conical EGaln electrode manipulated by a syringe, since the contact area, distribution of defects and organic contaminants, thickness and topography of the EGaln / $\mathrm{Ga}_{2} \mathrm{O}_{3}$ surface are constant for a particular junction. As the SAM is ferrocene-terminated, the ferrocene HOMO lies adjacent to the top EGaln electrode and is separated from the bottom silver electrode by a long alkyl chain.

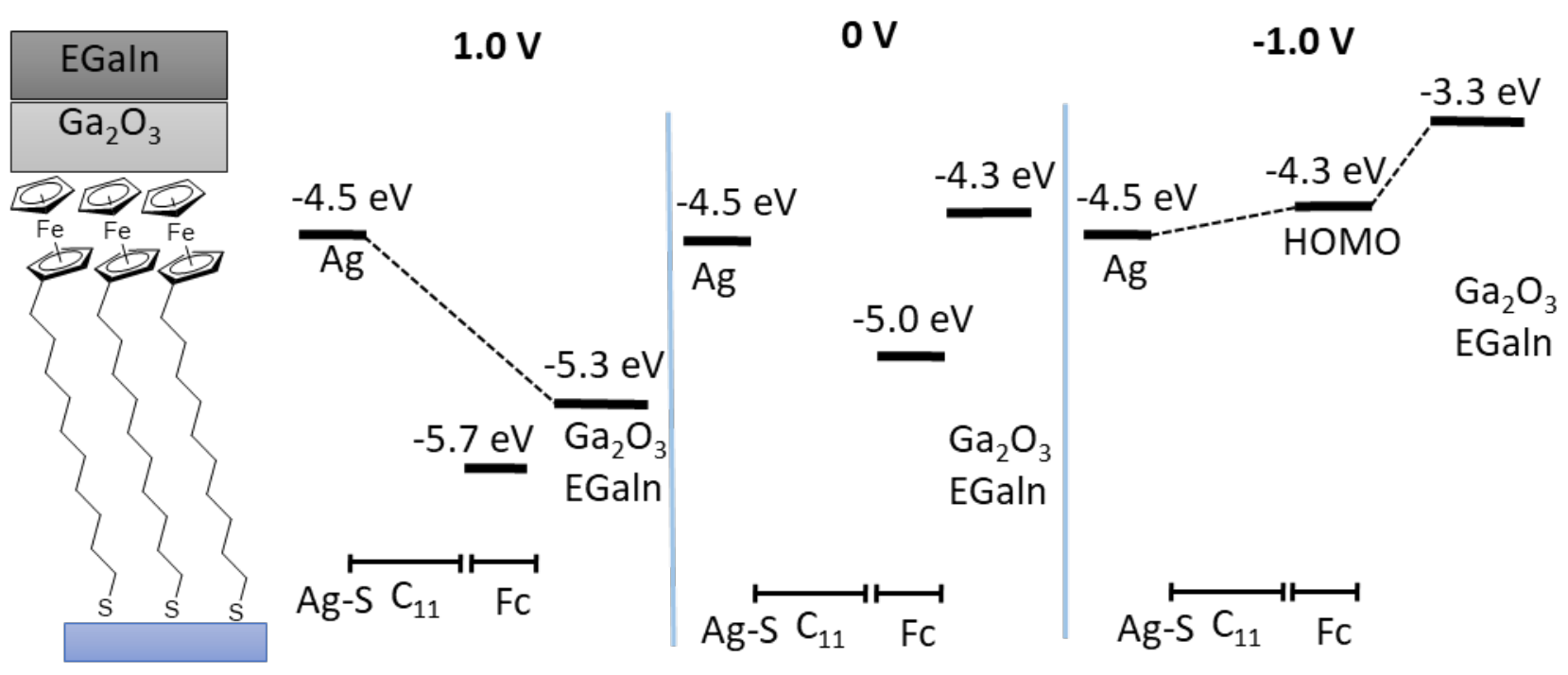

Figure 9 Schematic illustration of the $\mathrm{Ag}-\mathrm{S}(\mathrm{CH} 2) 11 \mathrm{Fc} / / \mathrm{GaO}_{x} / \mathrm{EGaln}$ junction, and Energy-level diagrams of the junction at $+1.0 \mathrm{~V}, 0 \mathrm{~V}$, and $+1.0 \mathrm{~V}^{84}$

When a positive bias is applied to the junction, there is no charge transfer through the molecule as the ferrocene HOMO lies too low in energy relative to the Fermi levels of the electrodes. At negative bias, however, the energy of the HOMO is raised to align between the Fermi levels of the electrodes, permitting a current to flow through the SAM. This implies that the rectification behaviour is molecular in origin. The length of the tunnelling barrier is approximately the length of the alkyl chain at negative bias, whereas this extends to the length of the entire molecule at positive bias. This change in the tunnelling barrier length causes rectification behaviour since the tunnelling current density, J, falls exponentially with increasing tunnelling barrier length. Hence, a much smaller current is observed at positive bias as the tunnelling barrier is longer than it is at negative bias. By adding another ferrocene unit in line with the original ferrocene unit it is found that the rectification ratio is increased. This supports the theory that the rectification is molecular as the total molecular length is increased while the alkyl chain length remains the same, resulting in a greater current attenuation at positive bias. Rectification mechanisms involving the $\mathrm{Ga}_{2} \mathrm{O}_{3}$ or the silver do not account for the large rectification ratios observed and their dependency on the molecular structure of the SAM, implying this property is intrinsic to the molecule.

Conventional current rectifiers exhibit rectification ratios of approximately $10^{5}$, whereas single-molecule rectifiers are limited to ratios in the order of $10^{3}$. However, Nijhuis et al have recently modified the molecular junctions described above to develop a molecular rectifier with a 
rectification ratio of $6.3 \times 10^{5}$ (Figure 10). ${ }^{85}$ They used a platinum bottom electrode in conjunction with an EGaln top electrode and an alkylthiolate SAM terminated by a diferrocenyl acetylene moiety, (HS- $\left.\left(\mathrm{CH}_{2}\right)_{15}-\mathrm{Fc}-\mathrm{C} \equiv \mathrm{C}-\mathrm{Fc}\right)$. Platinum was chosen as the bottom electrode as it has sufficiently strong binding to the SAM (unlike silver) and induces a tilt angle of $52^{\circ}$ (compared with $62^{\circ}$ for gold) which allows efficient molecular packing, reducing defects and consequent current leakage. With the longchain alkyl groups encouraging efficient packing, the SAM can survive bias sweeping of $\pm 3.0 \mathrm{~V}$ without irreversible damage. The two ferrocene units are spaced by an alkyne group in order to ensure the difference in the HOMO energy of each moiety is small, which allows both orbitals to enter the conduction window at low bias.
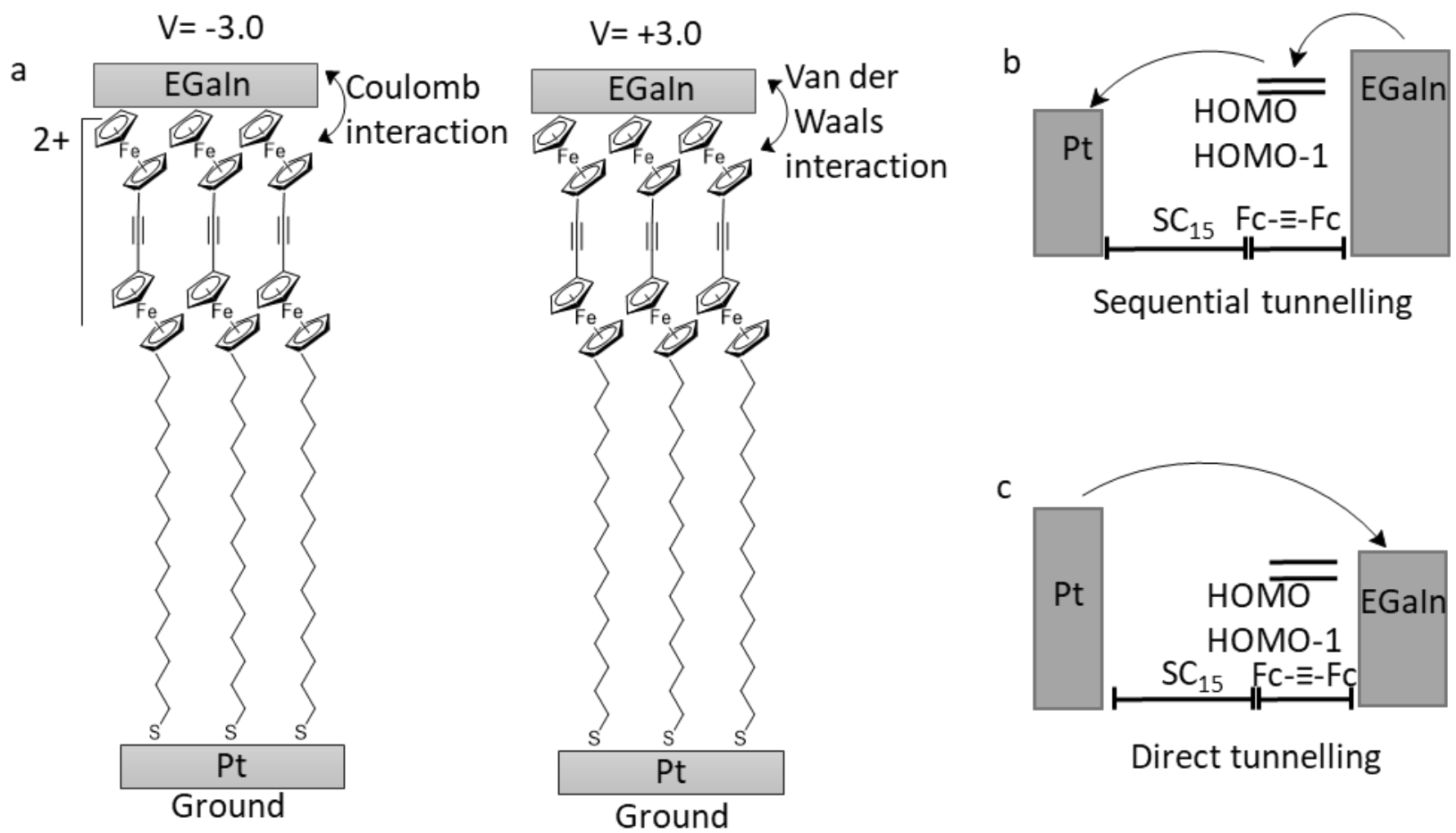

Sequential tunnelling

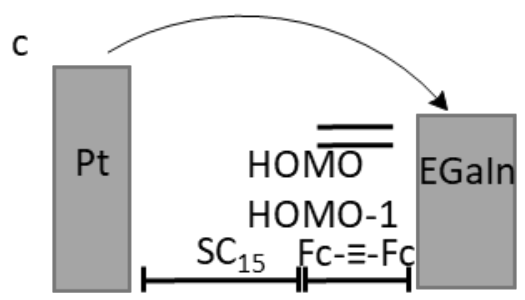

Direct tunnelling

Figure 10 (a) Schematic illustration of the $\mathrm{Pt}^{-\mathrm{SC}}{ }_{15} \mathrm{Fc}-\mathrm{C} \equiv \mathrm{C}-\mathrm{Fc} / / \mathrm{GaO}_{x} / \mathrm{EGaln}$ junction, double arrows show the Coulomb (at negative bias) or van der Waals (at positive bias) interaction between the Fc$\mathrm{C} \equiv \mathrm{C}-\mathrm{Fc}$ unit and the top electrode. Energy-level diagrams at (b) negative and (c) positive bias. ${ }^{85}$

At negative bias, a Coulomb interface forms between the SAM and the EGaln top electrode and a sequential hopping charge transport mechanism is proposed as the HOMOs of the ferrocene units enter the conduction window. The rectification ratio increases with bias until saturation is reached when the HOMOs have completely entered the conduction window and are pinned to the EGaln Fermi level. At positive bias, there is a van der Waals interface between the SAM and top electrode though which a very low current directly tunnels. This behaviour is molecular in origin and it is hypothesised that multiple molecules are contributing to charge transport in order to achieve a rectification ratio higher than $10^{3}$. Since the EGaln electrode is negatively charged at negative bias, positively charged ferrocene moieties are attracted to the electrode. Molecular dynamics calculations suggest that the larger the voltage applied, the more molecules are at the interface. So it is reasonable to assume that at $-3.0 \mathrm{~V}$ multiple molecules may be participating in charge transport. 
In another study, a methyl viologen-terminated SAM has been used simultaneously as a current rectifier and a resistive switch, such as those found in restive random-access memories (Figure 11).$^{86}$ A rectification ratio of $2.5 \times 10^{4}$ and a resistance on/off ratio of $6.9 \times 10^{3}$ at a low drive voltage of $0.89 \mathrm{~V}$ has been achieved in such devices. This dual-functionality is promising as rectifiers and resistive switches are typically two separate components, so the footprint of the device can be significantly reduced. Further, the drive voltage is applied only to single junction so can be lower than if applied across two junctions. The methyl viologen (MV) exists in 3 states: $\mathrm{MV}^{0}, \mathrm{MV}^{\circ+} \cdot \mathrm{X}^{-}$and $\mathrm{MV}^{2+} \cdot 2 \mathrm{X}$, where $\mathrm{X}$ is a counter ion. The radical cation state dimerises by $\pi-\pi$-stacking and electron spin pairing to form a dimer complex, provided that the SAM is densely packed. All the junctions studied demonstrate a uni-polar hysteresis which is strongly dependent on the size of the counterion. It is found that the on/ off ratio decreases with increasing counter ion size across the halogen series and becomes very low when bulky ions are used, such as $\mathrm{ClO}_{4}{ }^{-}$or $\mathrm{PF}_{6}{ }^{-}$. The highest on/ off ratio of $6.9 \times 10^{3}$ and rectification ratio of $2.5 \times 10^{4}$ was found when iodide was used as the counter ion. Larger counter ions require a lower voltage to switch between the on and off states and can demonstrate switching speeds as fast as $0.1 \mathrm{~ms}$ at $1.6 \mathrm{~V}$ drive voltage. Further, the iodide ions can be driven at bias as low as $0.89 \mathrm{~V}$ due to the bifunctionality of the junction (compared with $2.0-$ $6.0 \mathrm{~V}$ for separate memory and rectification elements).
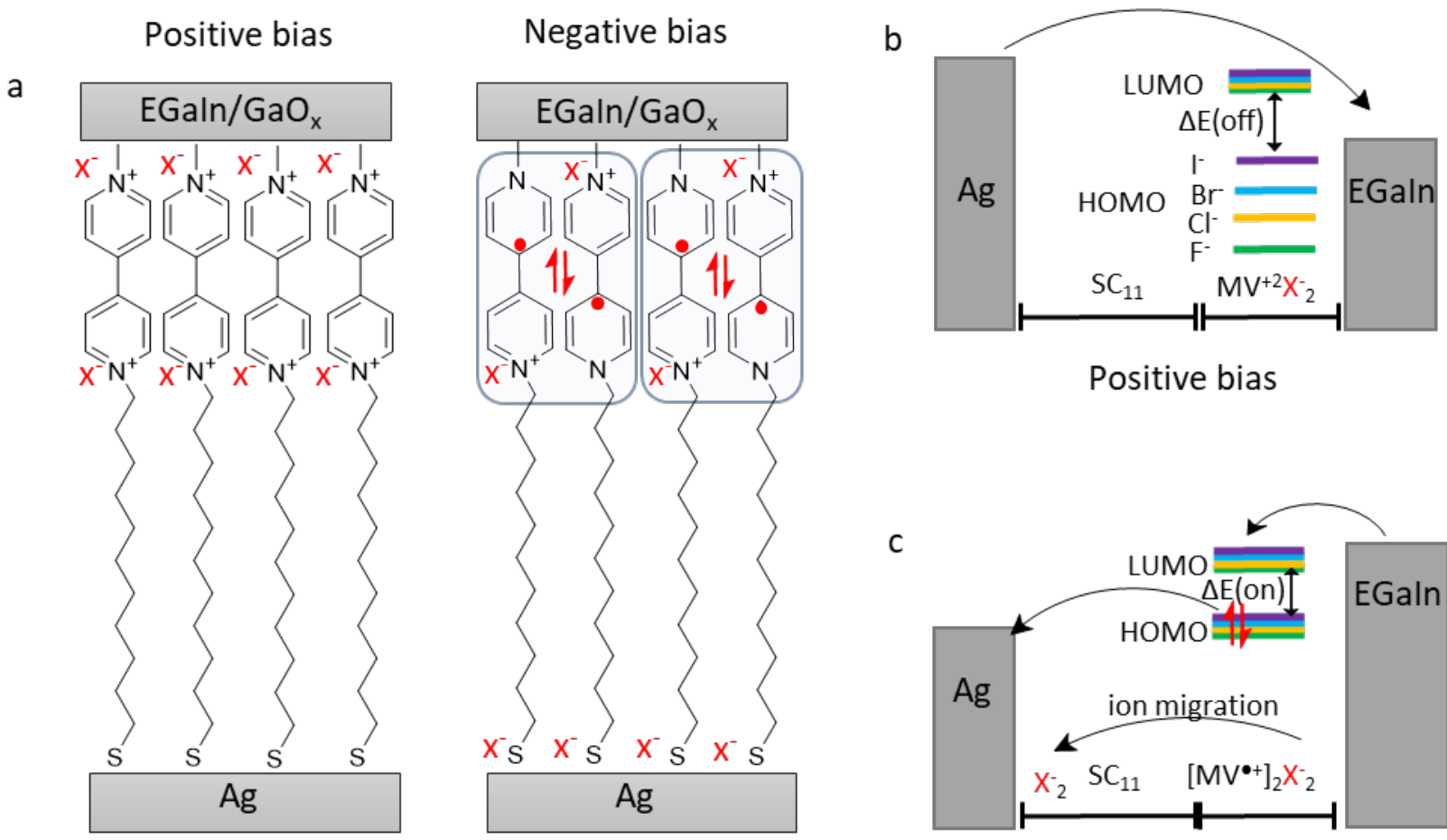

Positive bias

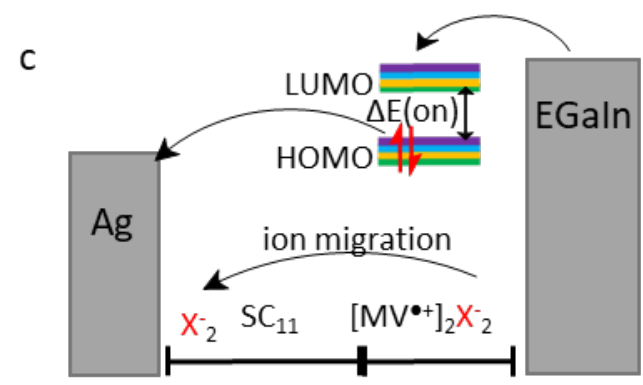

Negative bias

Figure 11 (a) Schematic illustration of the $\mathrm{Ag}-\mathrm{S}_{(}\left(\mathrm{CH}_{2}\right)_{11} \mathrm{MV}^{2+} \mathrm{X}_{2} / / \mathrm{GaO}_{x} / E G$ aln junction at positive bias and $\mathrm{Ag}-\mathrm{S}\left(\mathrm{CH}_{2}\right)_{11}\left[\mathrm{MV}^{\bullet+}\right] \mathrm{X}_{2}^{-} / / \mathrm{GaO}_{x} / \mathrm{EGaln}$ junction at negative bias, where $\mathrm{X}^{-}=\mathrm{I}^{-}, \mathrm{Br}^{-}, \mathrm{Cl}^{-}, \mathrm{F}^{-}$. Energylevel diagrams at (b) positive and (c) negative bias. ${ }^{86}$ 
It is thought that large counter ions bind more weakly to the methyl viologen dimer than smaller ions, so are more mobile within the SAM allowing them to be driven at low voltage. However, as the counter ions become too bulky, they can disrupt the SAM packing causing defects and consequent leakage currents. Ions that are too small bind too strongly to the dimer resulting in poor reversibility of the dimerisation. It is proposed that switching proceeds via a two-step mechanism starting with charging of the methyl viologen and EGaln electrode, followed by dimerisation and counter ion transport through the SAM. Without the charged methyl viologen units, no switching or rectification behaviour is observed. Junctions fabricated with EGaln stabilised in microchannels show on/ off ratio an order of magnitude higher $\left(10^{4}\right)$ than those fabricated with a conical EGaln electrode $\left(10^{3}\right)$. These stabilised junctions show a resilience against cycles of $\pm 1.5 \mathrm{~V}$ for $2 \times 10^{6}$ sweeps, indicating that no electrochemical reactions are occurring at the SAM/ $\mathrm{Ga}_{2} \mathrm{O}_{3}$ interface.

\section{Metal nanoparticle/nanoisland top contacts}

The deposition of metallic nanoparticles (NPs) on top of a functionalized monolayer by incubation of the substrate-supported monolayer in a metal nanoparticle dispersion has been widely used to deposit nanoparticle 'top contacts' and create metal | monolayer | NP junctions. ${ }^{87}$ A critical aspect of the assembly of these structures is the termination of the monolayer by a functional group suitable for contacting to the nanoparticle. In the case of gold particles, thiol(ate) contacts are an obvious choice, ${ }^{88,89}$ but alternative contacts have been developed that avoid the various challenges of the rather capricious thiol functional group. For example, terminal alkynes ( $\mathrm{HC} \equiv \mathrm{CR}$ ) are known to

react with under-coordinated gold surfaces to give direct $A u-C \equiv C R$ structures. ${ }^{90,91}$ The incubation of a directionally oriented LB monolayer bearing exposed terminal alkynes in a fresh uncapped gold nanoparticles (GNPs) solution results in creation of a metallic top electrode through the covalent attachment of the GNPs on top of the film via a heterolytic cleavage of the alkyne $\mathrm{C}-\mathrm{H}$ bond and formation an alkynyl carbon-Au $\sigma$-bond (Figure 12). ${ }^{59}$ In a similar way, deprotection of a trimethylsilyl-protected octa-1,3,5,7-tetrayne monolayer via fluoride-induced desilylation chemistry has allowed the formation of an unusual polyynyl monolayer, which when incubated in a solution of freshly prepared un-capped GNP results in formation of robust $A u|C \equiv C C \equiv C C \equiv C C \equiv C| A u N P$ junctions. ${ }^{92}$ This simple wet chemical procedure reliably creates robust and reproducible junctions in which the $10-50 \mathrm{~nm}$ diameter GNP top-contacts are chemically bound to the monolayer without damaging the underlying organic monolayer film and free of metallic short-circuits through the monolayer. 


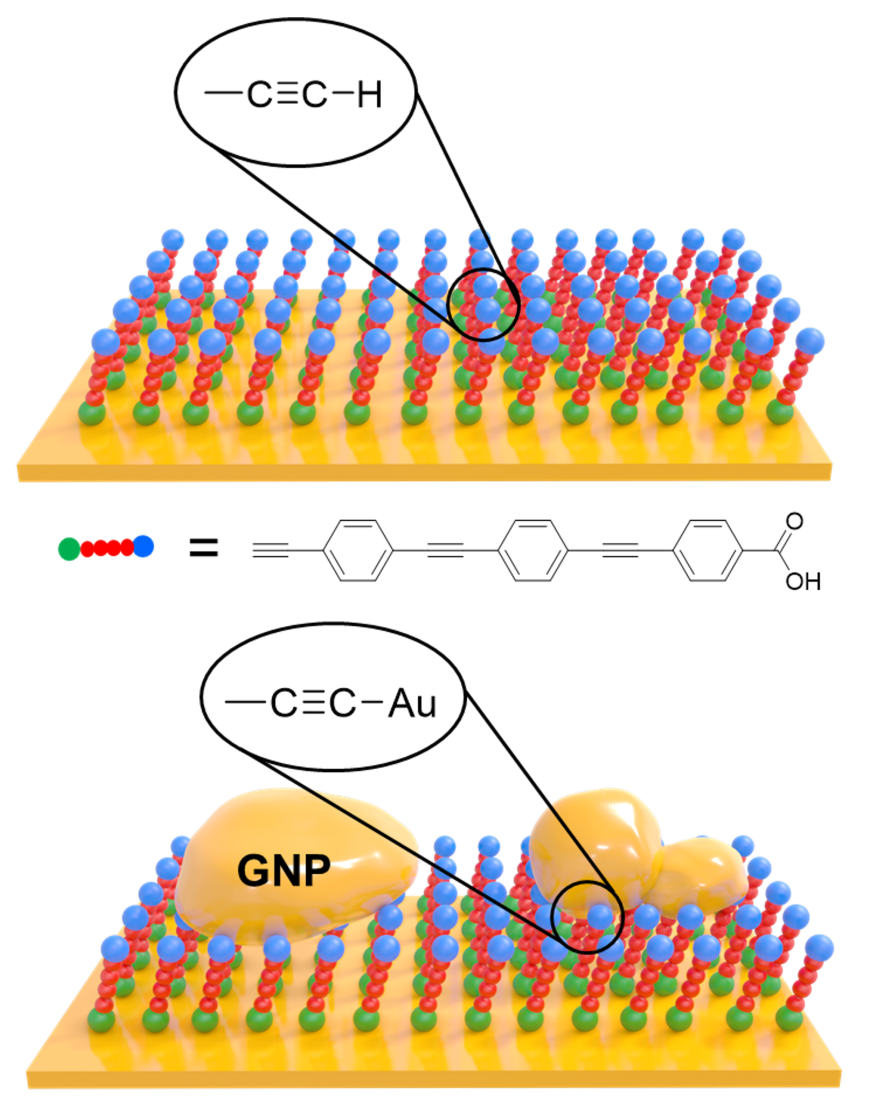

Figure 12 An ethynyl-functionalised LB monolayer (a) before and (b) after incubation in dispersion on GNPs. $^{59}$

Solid electrode-based bilayer molecular junctions have been constructed using gold nanoparticles as linkers to join two Co(II) bis(terpyridine) (\{Co\}) based SAMs supported on separate electrode surfaces. The NP is strongly electronically coupled through the SAMs to the Au electrodes resulting in length independent high conductance through the complete bilayer $\mathrm{Au}|\{\mathrm{CO}\}| \mathrm{NP}|\{\mathrm{CO}\}| \mathrm{Au}$ junction (Figure 13). ${ }^{93}$ Nanostructured linear arrays of thin film gold electrodes were firstly patterned onto two graphene/polydimethylsiloxane (PDMS)/polyethylene terephthalate (PET) substrates, and a monolayer of cobalt(II) bis-terpyridine molecules subsequently grafted to give the initial $\mathrm{Au} \mid\{\mathrm{CO}\}$ structures. Secondly, gold nanoparticles were immobilized on top of one of these monolayer functionalised electrode arrays by incubating the modified substrate into a solution of gold nanoparticles to give an $\mathrm{Au}|\{\mathrm{CO}\}| \mathrm{NP}$ structure. Finally, the two electrodes were contacted in a cross-bar configuration with the gold nanoparticles now contacting across the cobalt complexes. Electrochemical and DFT studies revealed that the nanoparticles significantly shift the frontier molecular orbitals close to the electrode Fermi levels, resulting in facile sequential tunnelling through the entire bilayer device. 


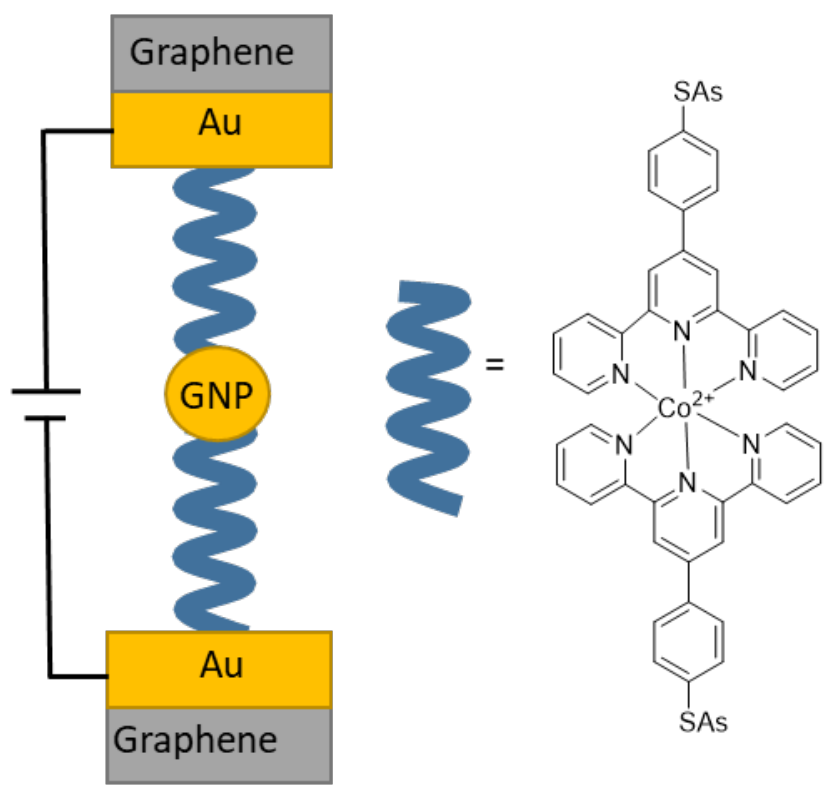

Figure 13 Schematic illustration of the molecular junction where two molecular wires are linked by gold nanoparticle. ${ }^{93}$

As an alternative to depositing pre-formed nanoparticles on a monolayer, the Thermal Induced Decomposition of an Organometallic Compound (TIDOC) method allows synthesis of metallic nanoparticles directly on the monolayer film from a single precursor (Figure 14). The TIDOC method is based on the incorporation of a terminal, thermally sensitive gold(I) acetylide complex (typically $-\mathrm{C} \equiv \mathrm{CAuPPh}$ or $-\mathrm{C} \equiv \mathrm{CAu}\left(\mathrm{CNC}_{6} \mathrm{H}_{4} \mathrm{OMe}-4\right)$ ) into the molecular precursor of the monolayer film. After Langmuir-Blodgett or self-assembly of the film on a bottom substrate electrode, the film is annealed at moderate temperatures resulting in cleavage of the Au-P or Au-C bond and reduction in situ of the $A u(I)$ to $A u(0)$ in the form of gold nanoislands. These metal deposits are distributed on the surface of the film without producing short-circuits by penetration through the conductive organic layer. ${ }^{94,95}$ Although incomplete metallization of the monolayer is unavoidable, since the precursor film offers only a maximum surface coverage of $7.2 \times 10^{-10}$ moles of gold atoms $\cdot \mathrm{cm}^{-1}$ these metallic nanoparticles could be used as seeds for increasing metallization by depositing a thicker, more uniform metal top contact electrode using other methods such as electroless metal deposition or direct metal evaporation. 


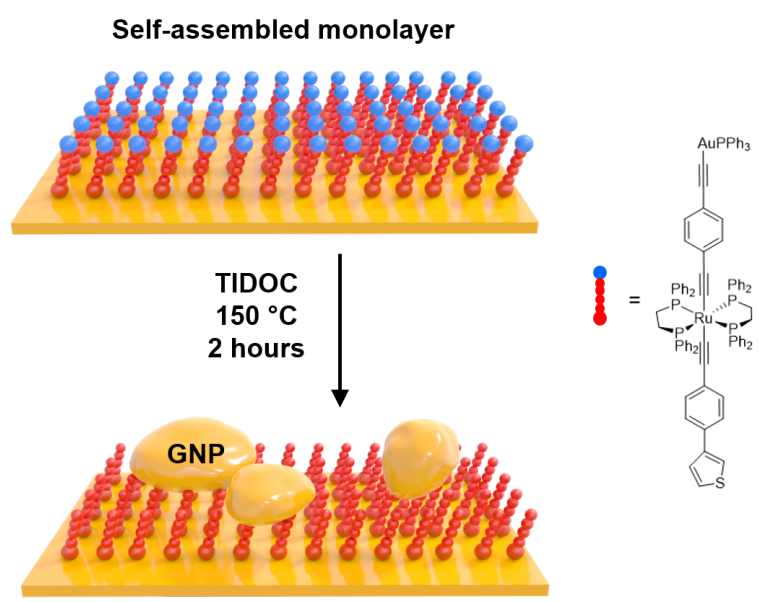

Figure 14 Schematic illustration of TIDOC process where annealed monolayer result in thermal decomposition and a formation of gold nanoparticles. ${ }^{95}$

Other in situ methods for deposition of a metallic structure on a monolayer include the photoreduction of a metal precursor. ${ }^{60,96}$ An OPE derivative functionalised by an amine $\left(\mathrm{NH}_{2}\right)$ or carboxylic acid $(\mathrm{COOH})$ was assembled into a Langmuir film on an aqueous sub-phase containing a metal precursor ( $\mathrm{HAuCl}_{4}$ or $\mathrm{AgNO}_{3}$ respectively). When transferred to a solid substrate the resulting Langmuir-Blodgett film bears photosensitive $\mathrm{AuCl}_{4}{ }^{-}$or $\mathrm{Ag}^{+}$ions on the top surface. After film exposure to a simple $254 \mathrm{~nm}$ UV light, the metal ions are reduced in situ to generate metal nanoislands on top of the conductive OPE monolayer (Figure 15). With this methodology, a surface coverage of the monolayer surface as high as $76 \%$ has been obtained without penetration of the nanoparticles nor damaging the underlying organic film. Similar methods based on reduction of silver ions coordinated to a thiol-functionalized monolayer surface by wet chemical or nanolithiographic electrochemical reduction with a C-AFM tip has also been developed. ${ }^{97}$ The use of nanopatterned surfaces ${ }^{98}$ for site-specific coordination of metal complex precursors prior to reduction has also been used to give metal patterns on monolayers. ${ }^{99,} 100$ 


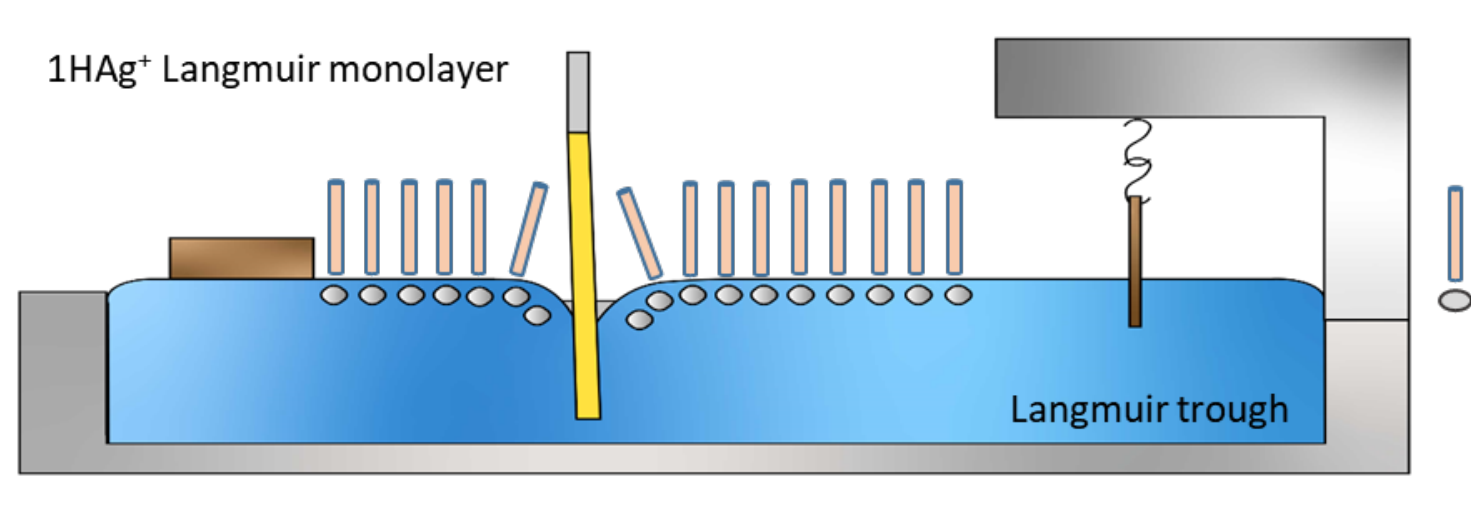

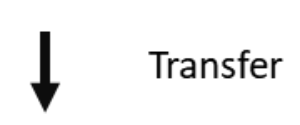

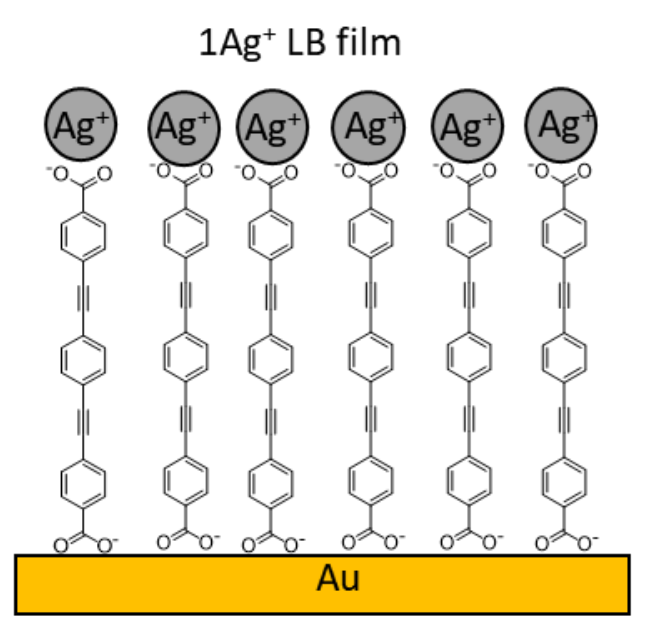

1AgNP LB film

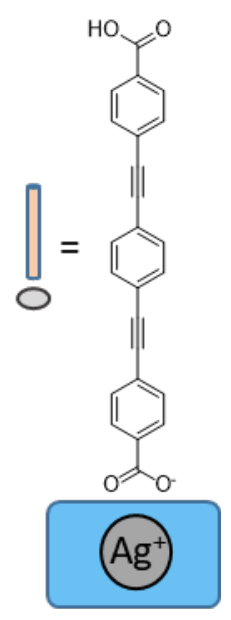

Figure 15 (a) The carboxylic acid moieties are deprotonated on the aqueous sub-phase containing $\mathrm{AgNO}_{3}$ and forms double ionic layer with cations $\left(\mathrm{Ag}^{+}\right)$; (b) the resultant $1 \mathrm{Ag}^{+}$Langmuir-Blodgett (LB) monolayer formed by immersion of a gold substrate into the water sub-phase; (c) silver nanoparticles formed as a result of photoreduction of the silver cations. ${ }^{96}$

In the case of palladium, surface area coverage of up to $85 \%$ has been achieved by in situ deposition of anisotropic palladium nanostructures onto a self-assembled monolayer of an amineterminated oligo(phenyleneethynylene) derivative. ${ }^{101}$ In this strategy, the substrate-supported monolayer is placed into an autoclave containing a solution of $\mathrm{Na}_{2} \mathrm{PdCl}_{4}$ and $\mathrm{KBr}$. The autoclave is pressurized under $\mathrm{CO}(6 \mathrm{bar})$ and heated $\left(80^{\circ} \mathrm{C}\right)$. The palladium precursor likely coordinates to the monolayer, providing a seed site for the subsequent nanoparticle growth. During nanoparticle formation on the surface, the CO strongly binds to the basal [111] planes of the growing Pd nanoparticles. The 'CO-confined growth' directs the formation of anisotropic sheet-like palladium nanostructures directly on the film. ${ }^{102,103}$ These nanodeposits do not result in short-circuits through the organic film and junctions is reproducibly formed in high yield.

More recently, Puebla-Hellmann et al. ${ }^{104}$ have developed a strategy for the deposition of gold nanoparticles from solution to the top anchor group of a SAM, creating a film of immobilized particles which is non-destructive for the organic layer and is used later for the reinforcement of the top contact by direct metal evaporation (Figure 16). This process allows the fabrication of thousands of identical, ambient stable metal-molecule-metal devices. For that, a platinum bottom electrode is used (since it is compatible with complementary metal-oxide-semiconductor (CMOS) fabrication) 
for assembling the molecular monolayer without affecting the quality of the SAMs, ${ }^{105}$ and also engineering a lower contact resistance with the sulfur anchors than the one on gold. ${ }^{106}$ Once the monolayer is assembled, the molecules are constrained laterally into circular pores of variable diameter (from $70 \mu \mathrm{m}$ down to $60 \mathrm{~nm}$ ) by a dielectric matrix and the gold nanoparticles (which can readily be replaced by platinum or palladium particles more compatible with CMOS-material) are bonded from a solution to the top anchor group of the molecular layer creating a film of immobilized nanoparticles, which is later reinforced by direct metal evaporation to seal the device. Although prototypical densely packed SAMs consists of alkane(di)thiol molecules were used, it can be extended to other molecules as it was demonstrated that the intrinsic molecular properties are not affected by the nanoparticle film and subsequent top metallization; providing, therefore, a new route to the large-scale integration of molecular compounds, even scaled down to the singlemolecule level, into solid-state devices.

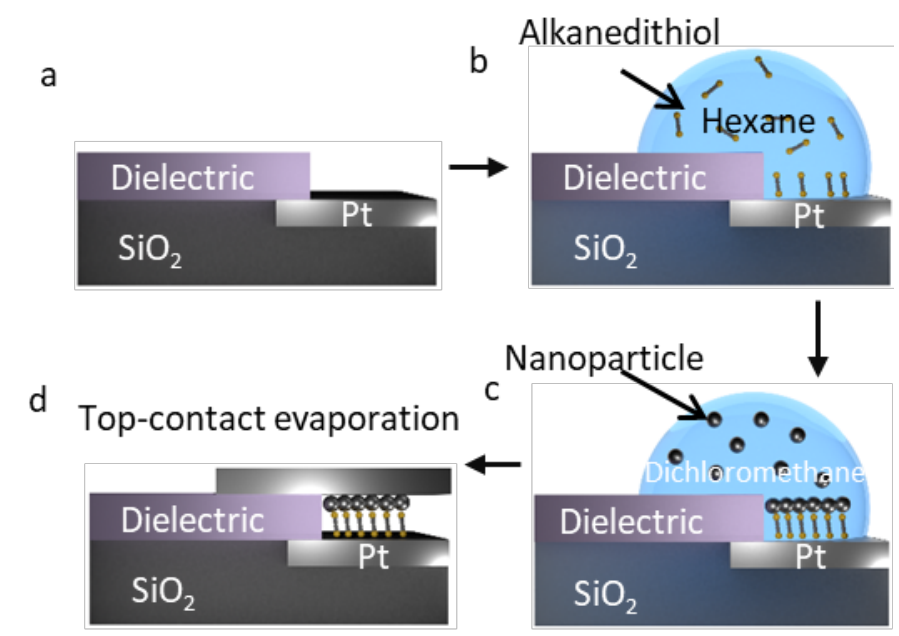

Figure 16 (a) Platinum bottom electrode for molecular assembly; (b) formation of self-assembled monolayer on the platinum electrode; (c) binding of gold nanoparticles from the solution to the top anchor group of the monolayer; (d) top-contact evaporation. ${ }^{104}$

\section{Direct Deposition}

One of the simplest and more widely used methods used to deposit a metallic layer onto a general surface is Physical Vapour Deposition (PVD). In PVD, a metal source is evaporated in a vacuum chamber to give a metal atom vapour which is subsequently condensed onto a substrate surface and form a thin metallic film (Figure 17). The thickness of the metal deposit can be controlled with the aid of a quartz crystal microbalance ( $Q C M$ ) or by the integrated flux from a controlled rate source (e.g. XPS). 


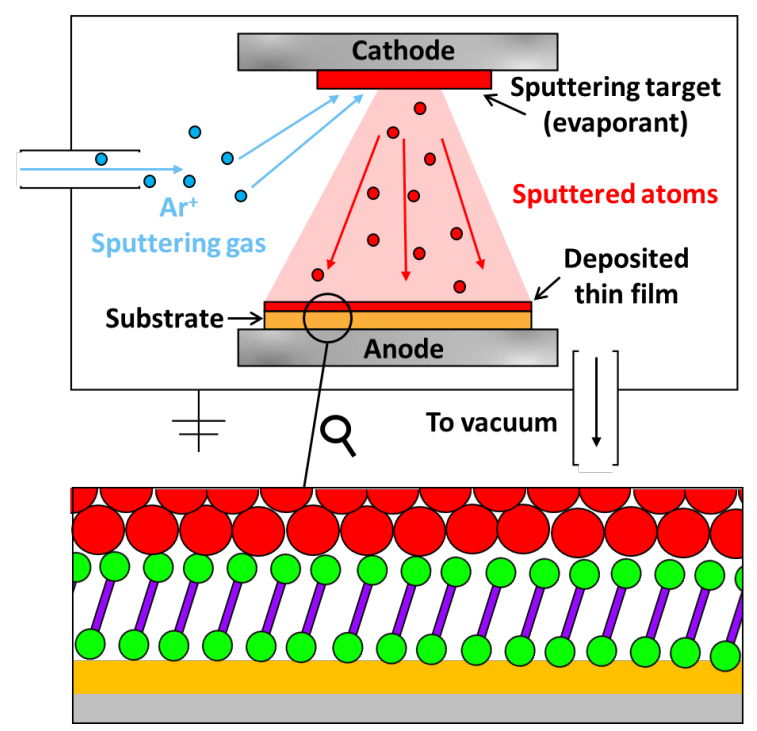

Figure 17 Schematic illustration of physical vapour deposition (PVD).

Despite being successfully used to deposit the top-contact electrode in the microelectronics industry (for instance in organic light emitting devices (OLEDs), polymer light-emitting diodes (PLEDs), photovoltaic (PV) cells, etc.) this methodology has significant drawbacks in molecular electronics. In PVD metal atoms reach the monolayer surface with a high kinetic energy which together with the radiation emitted from the heated source often results in chemical modification, such as the carbide formation that occurs during PVD of $\mathrm{Ti}^{107}$ or $\mathrm{Ca}^{108}$ onto $-\mathrm{OCH}_{3}$ terminated monolayers and other chemical transformations of surface functional groups. ${ }^{108,}{ }^{109}$ Further damage can arise from penetration of the high-energy metal atoms through the monolayer, given the dimension of a 'typical' OPE-type molecular wire, which might be only 1-3 nm thick. ${ }^{108,110,111}$ Such penetration may result in generation of an adlayer between the bottom-electrode and the monolayer, ${ }^{110,112}$ in formation of metallic filaments with a mushroom type structure that results in short-circuits, ${ }^{113}$ or insulating pillars if the evaporated metal can be easily oxidized (e.g. $\mathrm{Al}^{114}$ ).

Several strategies have been explored to overcome these shortcomings in the use of PVD to form the top contacts in large area molecular junctions. For instance, filling the evaporator chamber with an inert gas considerably reduces the energy at which metal atoms reach the surface and, therefore, damage to the monolayer can be minimized. ${ }^{115}$ However, this methodology may compromise the deposition efficiency. Additionally, coolers have been used to decrease the substrate temperature in an effort to avoid the high temperatures that contribute to damage of the organic monolayer. The use of indirect evaporation and blocking the 'line of sight' between the substrate and the metal source through use of baffles has also been shown to decrease the effects of penetration of metal atoms through the monolayer. ${ }^{115-117}$ The nature of the metal has also been described to be influential in the damage to the organic layer. For instance, Haick et al. ${ }^{115}$ showed that while gold atoms can diffuse between molecules in the monolayer, palladium metal atoms condense through a 2-D growth mechanism, which limits its interaction with the terminal group of the molecules in the film.

Chemical Vapour Deposition (CVD) is widely used for the deposition of thin solid films of controlled thickness and composition in the fields of microelectronics, optoelectronics, energy conversion devices, coatings, fibre production and fibre coating. ${ }^{118}$ In this method, one or more 
gaseous reactants diffuse to a substrate surface where they adsorb and undergo various dissociation and/or chemical reactions that lead to the formation of a stable thin film; it is a chemically selective technique in which a wide variety of materials can be deposited. Despite these advantages, CVD has been only occasionally used in the deposition of the top-contact electrode in molecular electronics. Early attempts successfully resulted in metallization of monolayers of organic compounds with aluminium oxides and hydroxides and whilst alumina and aluminium can be selectively deposited on patterned monolayers by careful control of the experimental conditions; in these cases, the growth rate proved to be rather low. ${ }^{119} 120$ The growth rates can be increased by thermal activation (ca. $70^{\circ} \mathrm{C}$ ) but this may induce damage in the monolayer. ${ }^{121}$ Shi et al. probed that an increase of the deposition rate of Al in CVD processes can be achieved by using UV light at room temperature while maintaining the selectivity of the deposition. ${ }^{122}$ Moreover, this photoactivated CVD reaction is selective, i.e. patterned surfaces can be used as templates for metal deposition.

Deposition of a conducting interlayer has been used to protect the organic monolayer from direct evaporation of a metal (Figure 18). Examples include thin spin-coated films of the conducting polymer poly(3,4-ethylenedioxythiophene) polystyrene sulfonate, PEDOT:PSS. This polymeric film avoided the formation of short-circuits upon deposition of gold by CVD. ${ }^{25,123,124}$ In addition, parasitic currents and crosstalk were prevented by processing within lithographically defined vertical interconnects. Other $\pi$-conjugated undoped polymers have also been successfully used as interface layers to avoid short-circuits due penetration of the top contact electrode through the monolayer. Large area molecular electronic devices $\left(1 \mathrm{~mm}^{2}\right)$ prepared by deposition of poly $[(\mathrm{m}$ phenylenevinylene)-co-(2,5-dioctoxy-p-phenylenevinylene)], PmPV, with a $\mathrm{Hg}$ top contact electrode resulted in a $75 \%$ yield. ${ }^{125}$ However, the resistance of the devices prepared using this conducting interlayer is significantly different to those of molecular junctions that do not incorporate the polymer interlayer ${ }^{123,126,127}$ due to poor contact between the polymer and the molecules in the monolayer. In particular, the conductance of molecular devices incorporating PEDOT:PSS is limited by the low vertical conductance of PEDOT:PSS itself. ${ }^{128}$ Additionally, the yield of these metal|molecule |polymer|metal devices has been reported to be dependent on the type of isolating layer (photoresist or $\left.\mathrm{SiO}_{2}\right)^{25,127}$ and also on the molecular contact groups (hydrophilic or hydrophobic). ${ }^{25}$
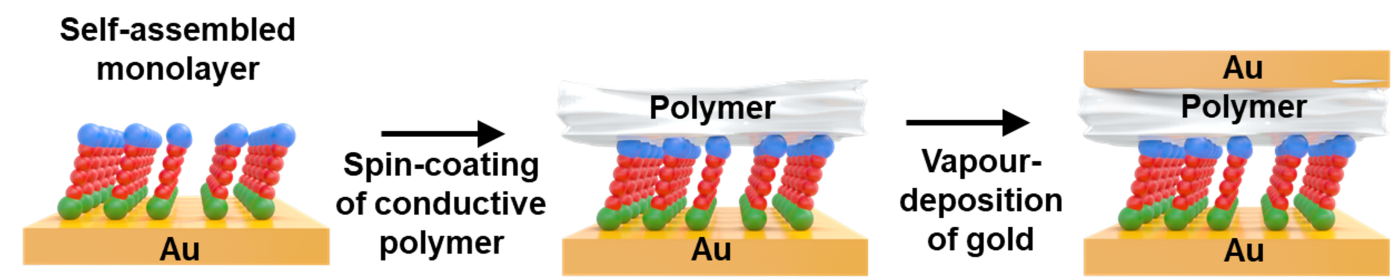

Figure 18 Schematic illustration of a deposition of a conducting interlayer to protect monolayer from a direct deposition of a metal. ${ }^{25}$ 
For these reasons, the concept of using an interconnect between the top metal electrode and the monolayer has been extended to other materials. Graphene-based devices have shown a better electronic coupling between graphene and the molecules in the monolayer in comparison with equivalent PEDOT:PSS based devices. ${ }^{129,}{ }^{130}$ Importantly, graphene, ${ }^{130}$ multilayered graphene ${ }^{131}$ and reduced graphene oxide $(\mathrm{rGO})^{132}$ also may perform as the top-contact electrode obviating the need for an additional top metal contact. Additionally, solution-processed reduced graphene oxide ( $\mathrm{rGO}$ ) films ${ }^{133}$ and single carbon nanotubes ${ }^{134}$ were demonstrated as good interlayer electronic contacts. Introduction of an interlayer of electron beam deposited silicon (e-Si) ${ }^{135}$ or carbon $(\mathrm{e}-\mathrm{C})^{135}$ represents another widely used methodology to prevent filament formation and short-circuits in direct metal evaporation over the monolayer. For instance, this technique has been successfully used in the group of McCreery for the construction of carbon-based molecular junctions by grafting of a diazonium salt onto a pyrolyzed photoresist film (PPF). Then, an eC top contact is deposited followed by evaporation of a thin layer of gold. These devices [PPF|molecular layer|eC|Au] have been demonstrated to result in high yield $(>90 \%)$, good reproducibility, long cycle life and wide temperature tolerance in addition to be flexible and semi-transparent if the appropriate substrate is used. ${ }^{136}$

In this context the so-called "all-carbon" molecular junctions consisting of covalently bonded oligomers between two carbon based electrodes (e.g. fabricated by electron beam deposition) have been demonstrated to provide contacts with equal work functions and sufficient optical transparency to allow light transmission through the molecular junction, which opens the door to studies in the field of optomolecular electronics. Thus, photocurrents generated by illumination of carbon-based molecular electronic devices have been recently investigated as diagnostics of how molecular structure and orbital energies determine the electronic behaviour of the junction (Figure 19). ${ }^{137}$ Focused electron beam induced deposition (FEBID) has been employed to fabricate topcontact carbon electrodes without the need of resists nor masks; in addition, this methodology results in a well-defined location, shape and size of the C-FEBID top contact electrode as defined by the path of the e-beam. ${ }^{138}$ Conductive protective layers made of commercially available carbon paint have also been reported recently as conducting interlayers in molecular electronics. ${ }^{139}$ These carbon paints have a series of advantages including their ease processability, low contact resistance, high stability of the junctions, good reproducibility and $100 \%$ yield in non-shorting junction yields. Recently, an aluminium oxide $\left(\mathrm{AlO}_{\mathrm{x}}\right)$ layer was deposited by e-beam evaporation onto an electrografted monolayer to produce $\mathrm{Au}|\mathrm{eC}|$ monolayer | AlOx | eC | Au devices, which are similar to an electrochemical cell but lacking ions, double layers, and solvent and involve only a single half reaction. ${ }^{140}$ These molecular junctions represent an excellent benchmark that not only provides kinetic information about electron donor-acceptor reactions, basic electron transfer reactions underlying electrochemistry, and electrostatic effects in organic electronics, but also may have applications in the production of memory devices, charge storage, and capacitors. Metallic nanoparticles deposited by soft methodologies have also been used to protect the underlying monolayer upon the evaporation of a metal layer. Thus, it is well-known that incubation of a monolayer with the appropriate top-anchor group (e.g. $-\mathrm{SH},-\mathrm{NH}_{2},-\mathrm{C} \equiv \mathrm{C}-\mathrm{H}$, etc.) in a dispersion of the metallic nanoparticles results in formation of a chemical bond between the nanoparticle and the molecules. ${ }^{58,59}$ Subsequent evaporation of a metal results in the metallization of the film and completion of metal| monolayer|metal junctions with high yields (up to $95.5 \%$ ). ${ }^{104}$ 

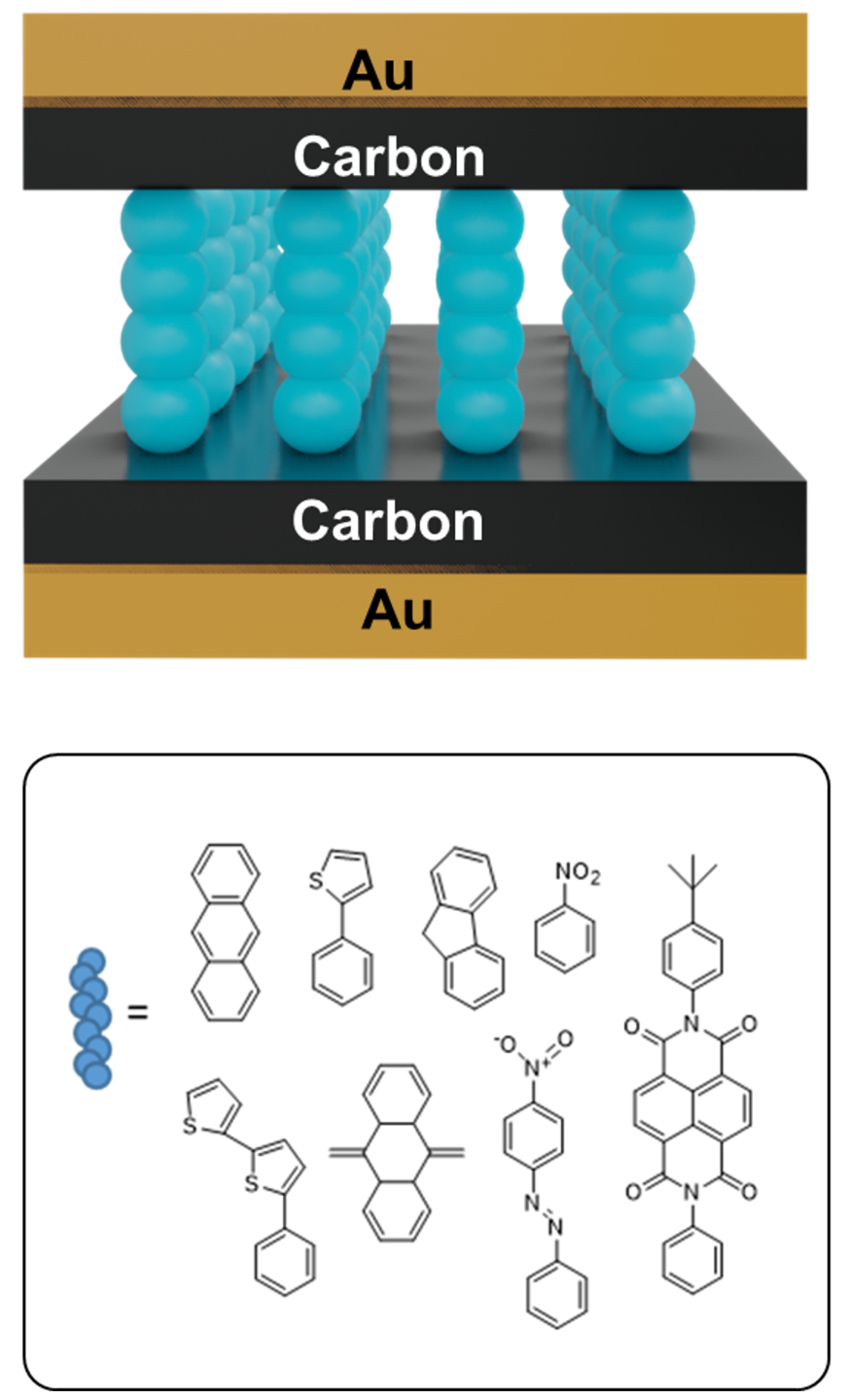

Figure 19 Carbon electrode deposited on top of the monolayer by focused electron beam induced deposition to form 'all-carbon' molecular junctions. ${ }^{137}$

Surface-diffusion-mediated deposition (SDMD) represents another alternative for the deposition of metallic contacts (e.g. $\mathrm{Au}, \mathrm{Pt}$ and $\mathrm{Cu}$ ) onto molecular layers that results in good yield $(>90 \%)$ and reproducibility. ${ }^{141}$ In this "soft" approach, the metal is not directly evaporated onto the monolayer but deposited onto a surface adjacent to and ca. $50 \mathrm{~nm}$ away from the monolayer. An additional $\mathrm{SiO}_{2}$ 'overhang' fabricated above the monolayer protects the molecules from direct impingement of metal atoms and source radiation. Subsequently, the surface diffusion of the metal adatoms deposited on the surface adjacent to the monolayer causes the migration of these metal atoms toward and onto the molecular layer, albeit this methodology has a significant addressability problem.

Atomic layer deposition (ALD) is another technique used for the metallization of monolayers of organic compounds in the context of molecular electronics and it is considered as a key enable technology for future (molecular) electronic devices for several reasons: ${ }^{142-144}$ (i) it typically proceeds at low temperature using metal-organic precursors under controlled conditions; (ii) ALD results in the formation of metal layers with chemical bonds to the organic molecules; (iii) formation of undesired intermediate compounds in the ALD chamber and their subsequent deposition on the 
monolayer surface can be minimized though careful control of the experimental conditions; (iv) the film thickness can be controlled at an Ångstrom or monolayer level since growth is truly atomic layer-by-layer and self-limiting, which results in extremely smooth films; (v) ALD coating is conformal and results in a pinhole-free deposition; (vi) ALD is scalable to very large substrates and to parallel processing of multiple substrates. Successful examples of ALD deposition onto organic monolayers can be found in the literature. For instance, Seitz et al. ${ }^{145}$ used ALD to deposit a thin layer of Cu by from the precursor $[\mathrm{Cu}(\mathrm{sBu}-\mathrm{amd})]_{2}$ (sBu-amd $=$ di-sec-butylacetamidinate). The thin $\mathrm{Cu}$ film deposited by ALD protects the SAM layer, opening the door to a subsequent deposition using traditional methods to form a thicker layer. Park et al. ${ }^{144}$ studied the deposition of Ru onto organic monolayers by ALD demonstrating that this methodology is very advantageous in fabricating metalinsulator-metal tunnel junctions (MIMTJ).

The conventional electrochemical methods applied to the formation of metallic deposits onto monolayers often result in formation of clusters on the surface as well as metal entry into the monolayer or even penetration of the metal to the bottom electrode and formation of floating monolayers onto this new metal layer. ${ }^{146,}{ }^{147}$ In some cases, bulky terminal groups have been demonstrated to reduce or prevent the metal penetration through the monolayer, and a few successful examples in which short-circuits were not observed have been described. ${ }^{148}$ For instance, electrochemical deposition of palladium onto a pyridine-terminated monolayer has been achieved; ${ }^{149}$ however, it should be noted that the metallic Pd was deposited in the form of nanoparticles across the surface rather than a homogeneous metal layer. In addition, both overpotential deposition (OPD) ${ }^{150}$ and underpotential deposition (UPD) ${ }^{147,151}$ of metals on monolayers have also been reported to result in short circuits since the metallic film formed is often accompanied by metallic filaments.

Despite these, in general, unsuccessful attempts to use electrochemistry for deposition of the top contact electrode, electroless deposition (ELD) has emerged as a complementary technique useful to achieve a full metallic coverage of the surface of the monolayer. ELD is a simple, cheap and soft method in which metallization occurs via the chemically promoted reduction of metal ions without application of any electrical current. ${ }^{152-155}$ since no external applied potential is required, ELD is fully compatible with insulating or low-conductivity monolayers after the surface is activated with some "seeds" that catalyse the redox process of the ions in the solution. The catalyst decreases the activation energy of metal formation by acting as a temporary electron bridge between the metallic precursor and the reducing agent. Typical industrial surface activation processes occur via surface treatment with stannous chloride and subsequent reduction of $\mathrm{Pd}^{2+}$ to a catalytic state, e.g. colloidal $\mathrm{Pd}^{0}$, by $\mathrm{Sn}$ ions adsorbed on the surface. ${ }^{156}$ However, this methodology involves the use of toxic tin compounds and several complex additives, surfactants, and other adsorption promoters. These reactants may contaminate the surface and have a non-negligible influence on the final electrical properties of the junctions. To avoid these problems, metal nanoparticles or nanoislands deposited onto the monolayer using any of the methodologies previously reported in this contribution (e.g. self-assembly methodologies and click chemistry ${ }^{58,59,155}$ ) can be used as the catalysts for a subsequent ELD. Often these methodologies result in a random distribution of the nanoparticles, that may also have an influence on the deposition behaviour as well as on the deposit quality and does not allow selective deposition.

Patterning methods such as photopatterning, microcontact printing (MCP) and scanning probe lithographies can be used to confer spatial selectivity to the "seeding" step. ${ }^{157-160}$ Thus, electroless nanowire deposition on micropatterned substrates has also been employed to address the growth of metallic nanowires on the monolayer surface. ${ }^{161}$ Additionally, ELD can also proceed without any 
fixation of the surface with a catalyst, ${ }^{152}$ e.g. deposition of a copper layer onto $-\mathrm{COOH}$ terminated monolayers, although penetration of metallic copper in the monolayer has been reported. ${ }^{152-154,158}$ Self-seeding of the monolayer with $\mathrm{Cu}^{2+}$, accompanied by the formation of $\mathrm{Cu}^{2+}$-surface complexes, has successfully resulted in a good control the morphology of the deposit without penetration of the top-contact metal in the monolayer. ${ }^{154}$ In addition, since this self-seeding $\mathrm{Cu}^{2+}$ ELD method is chemically sensitive to the functionalization of the monolayer, patterned monolayers can be employed as templates for the deposition of large area patterned devices. ${ }^{154}$

In an attempt to solve the problems of damage of the monolayer or formation of short-circuits often encountered in the techniques described above, soft lithographic contact processes have been developed and explored in the field of molecular electronics. In the so-called nanotransfer printing (nTP) method the metallic top-contact electrode is transferred onto the monolayer by soft mechanical contact (without applied pressure) from elastomeric poly(dimethylsiloxane) (PDMS) or perfluoropolyether (PFPE) stamps incorporating features or patterns defined by a master substrate (Figure 20). ${ }^{162,163}$ The transference results from the strong chemical affinity between the metal contact and the terminal anchoring group present in the monolayer; for instance, a thiol-terminated monolayer and a gold metal contact. ${ }^{163-165}$ Therefore, in the nTP method the monolayer is not exposed to external chemical agents (etchants, sacrificial resists, developers or solvents) and the process occurs in ambient conditions. In addition, multiple devices can be fabricated in parallel (arrays of electrodes) and the technique is potentially scalable resulting in permanent and device-todevice reproducible molecular junctions. Finally, the size and shape of the top contact electrode are defined by the feature size and shape formed on the stamp, and not by other factors such as the wavelength of light. The yield of the devices that have been reported in the literature as prepared by the nTP technique is rather variable. For instance, Au|monolayer|GaAs junctions were produced by nTP with a yield larger than $95 \%$ yield. ${ }^{162,166,167}$ In contrast, Au|monolayer|Si junctions fabricated by nTP exhibited a yield as low as $20 \%$ accompanied by a poor electrical behaviour. ${ }^{164}$

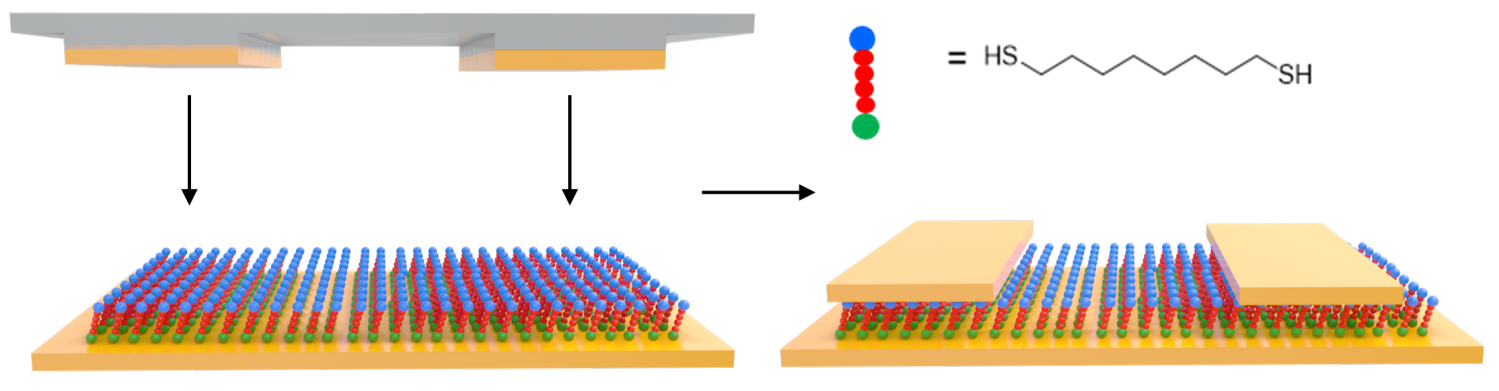

Figure 20 Schematic illustration of the nanotransfer printing (nTP) procedure. ${ }^{162}$

Lift-off assisted approaches have also been applied in molecular electronics for the fabrication of the top-contact electrode. In the "lift-off, float-on", LOFO, technique, ${ }^{168}$ a metallic film is first deposited on a solid substrate and subsequently the substrate is dissolved in a liquid media ("liftoff"); the metallic film is then floated-on to the monolayer deposited onto the bottom electrode, in a liquid-mediated process ("float-on"). An illustrative example of the LOFO method is the work from Vilan et al. ${ }^{169}$ who deposited tartaric acid derivatives by the self-assembly methodology onto GaAs(100). Gold dots, ca. $0.5 \mathrm{~mm}$ in diameter and $60 \mathrm{~nm}$ thick, were evaporated onto a glass substrate. These gold dots were released from the surface by immersion of the gold-modified glass substrate in a solution of HF in acetonitrile; subsequently, water was added to increase the surface 
tension, to allow the gold dots to float. The GaAs covered by the organic monolayer of tartaric acid is then lifted with deposition of the gold dots (top-electrode). Finally, the samples were dried at $60-$ $70{ }^{\circ} \mathrm{C}$ in a vacuum oven. Other bottom electrodes were used in later contributions that lead to Aumonolayer-Si ${ }^{170}$ and Au-monolayer-ZnO junctions. ${ }^{171}$

The LOFO method has a number of specific advantages over other methods. The LOFO method does not result in penetration of the top contact and it is appropriate for biomolecular electronics since the LOFO technique does not rely on the actual chemical binding of the molecules to the top contact electrode, and the monolayer is kept wet until the electrical contact takes place at (or very close to) room temperature. ${ }^{172}$ However, there are severe drawbacks (roughening of the metallic film during the etching process, wrinkling of the metallic layer upon the transfer process, presence of air gaps between the monolayer and the metallic film and lower molecular contact areas as compared to vapour-deposited contacts) that limit LOFO methodology for further applications and mass production. ${ }^{168,173-175}$

Shimizu et al. ${ }^{176}$ have made a further improvement of the LOFO method to overcome the wrinkling problem. The essence of the new method, known as polymer-assisted lift-off (PALO), combined concepts from LOFO and nTP methodologies. In the PALO technique, a hydrophobic polymer (e.g., poly(methyl methacrylate) (PMMA) or poly(styrene)) - that should have a high interfacial energy with the lift-off solvent chosen - is used as a backing layer on the top electrode, which renders the metallic film with both mechanical stability and a thermodynamic driving force that avoids wrinkling of the contacts. The PALO method has several advantages including, parallel device fabrication, nanoscale to centimeter device sizes, high-quality metal films, and non-damaging deposition (yields $>90 \%$ ). Extensions of the LOFO and PALO methods have also been considered for the creation of many junctions simultaneously, so as to facilitate collecting meaningful statistics for I(J) measurements on molecular junctions. ${ }^{177}$

\section{Conclusion}

The field of molecular electronics has been advanced through the development of methods for the formation of single-molecule and 'large-area' molecular junctions. Single-molecule junctions are almost ideal objects for research and discovery, allowing transport phenomena to be studied free from complications arising from near-neighbour effects and cross-talk between adjacent molecules. However, the sensitivity of the transport properties of a single-molecule junction to molecular geometry and variation in electrode-molecule contact results in a statistically significant variation in electrical characteristics from junction to junction. Large-area junctions can allow an averaging of molecular environment and more consistent electrical response, and naturally lend more readily to technologically relevant device structures. The past decades have seen an intense body of work addresses the problems of reliably creating these large area junctions, both as experimental objects for study and in the context of realising true electronic devices with functional molecular components. These techniques continue to be evolved, refined and optimised, and as the technologies for fabrication of 'large area' junctions mature, and as these methods are combined with the immense power of nanolithography developed within the conventional solid-state electronics industry, the field of molecular electronics cannot help but continue to reveal new fundamental science and exciting technological opportunities.

\section{Conflicts of Interest}


There are no conflicts to declare.

\section{Acknowledgement}

This project was supported by the Spanish Ministry of Science through the grant numbers MAT201678257-R and PID2019-105881RB-I00, including FEDER funding, by Gobierno de Aragón through the grant numbers LMP33-18, and E31_20R with European Social Fund (Construyendo Europa desde Aragón). Financial support from the Australian Research Council (DP190100073; DP190100074) and the University of Western Australia is gratefully acknowledged.

\section{References}

1. K. Wang and B. Q. Xu, Top. Curr. Chem., 2017, 375, 17.

2. N. J. Tao, Nat. Nanotechnol., 2006, 1, 173-181.

3. G. Reecht, F. Scheurer, V. Speisser, Y. J. Dappe, F. Mathevet and G. Schull, Phys. Rev. Lett., 2014, 112, 047403.

4. C. J. Lambert, Chem. Soc. Rev., 2015, 44, 875-888.

5. C. J. Lambert and S. X. Liu, Chem. Eur. J., 2018, 24, 4193-4201.

6. M. H. Garner, H. X. Li, Y. Chen, T. A. Su, Z. Shangguan, D. W. Paley, T. F. Liu, F. Ng, H. X. Li, S. X. Xiao, C. Nuckolls, L. Venkataraman and G. C. Solomon, Nature, 2018, 558, 415-419.

7. D. Z. Manrique, Q. Al-Galiby, W. J. Hong and C. J. Lambert, Nano Lett, 2016, 16, 1308-1316.

8. C. M. Finch, V. M. Garcia-Suarez and C. J. Lambert, Phys. Rev. B, 2009, 79.

9. Y. Komoto, S. Fujii, M. Iwane and M. Kiguchi, J. Mater. Chem. C, 2016, 4, 8842-8858.

10. F. Chen, J. Hihath, Z. F. Huang, X. L. Li and N. J. Tao, Ann. Rev. Phys. Chem., 2007, 58, 535564.

11. B. Q. Xu and N. J. J. Tao, Science, 2003, 301, 1221-1223.

12. R. J. Nichols, W. Haiss, S. J. Higgins, E. Leary, S. Martin and D. Bethell, Phys. Chem. Chem. Phys., 2010, 12, 2801-2815.

13. W. J. Hong, H. Valkenier, G. Meszaros, D. Z. Manrique, A. Mishchenko, A. Putz, P. M. Garcia, C. J. Lambert, J. C. Hummelen and T. Wandlowski, Beilstein J. Nanotech., 2011, 2, 699-713.

14. J. T. Zheng, R. W. Yan, J. H. Tian, J. Y. Liu, L. Q. Pei, D. Y. Wu, K. Dai, Y. Yang, S. Jin, W. J. Hong and Z. Q. Tian, Electrochim. Acta, 2016, 200, 268-275.

15. H. Park, A. K. L. Lim, A. P. Alivisatos, J. Park and P. L. McEuen, Appl Phys Lett, 1999, 75, 301303.

16. J. Park, A. N. Pasupathy, J. I. Goldsmith, C. Chang, Y. Yaish, J. R. Petta, M. Rinkoski, J. P. Sethna, H. D. Abruna, P. L. McEuen and D. C. Ralph, Nature, 2002, 417, 722-725.

17. X. D. Chen, S. Yeganeh, L. D. Qin, S. Z. Li, C. Xue, A. B. Braunschweig, G. C. Schatz, M. A. Ratner and C. A. Mirkin, Nano Lett., 2009, 9, 3974-3979.

18. X. D. Chen, A. B. Braunschweig, M. J. Wiester, S. Yeganeh, M. A. Ratner and C. A. Mirkin, Angew. Chem. Int. Ed., 2009, 48, 5178-5181.

19. G. F. Zheng, X. D. Chen and C. A. Mirkin, Small, 2009, 5, 2537-2540.

20. G. Binning and H. Rohrer, The Nobel Lecture: Scanning Tunneling Microscopy - From Birth to Adolescence, https://www.nobelprize.org/prizes/physics/1986/binnig/lecture/).

21. B. Mann and H. Kuhn, J. Appl. Phys., 1971, 42, 4398-4405.

22. R. M. Metzger, Chem. Rev., 2015, 115, 5056-5115.

23. R. M. Metzger, Chem. Rev., 2003, 103, 3803-3834.

24. A. Vilan, D. Aswal and D. Cahen, Chem. Rev., 2017, 117, 4248-4286. 
25. H. B. Akkerman, P. W. M. Blom, D. M. de Leeuw and B. de Boer, Nature, 2006, 441, 69-72.

26. J. E. Green, J. W. Choi, A. Boukai, Y. Bunimovich, E. Johnston-Halperin, E. Delonno, Y. Luo, B. A. Sheriff, K. Xu, Y. S. Shin, H. R. Tseng, J. F. Stoddart and J. R. Heath, Nature, 2007, 445, 414417.

27. A. J. Bergren, L. Zeer-Wanklyn, M. Semple, N. Pekas, B. Szeto and R. L. McCreery, J. Phys. Condens. Matter, 2016, 28, 094011.

28. S. K. Saxena, U. M. Tefashe, M. Supur and R. L. McCreery, ACS Sensors, 2021, 6, 513 - 522.

29. H. Haick and D. Cahen, Prog. Surf. Sci., 2008, 83, 217-261.

30. L. A. Bumm, ACS Nano, 2008, 2, 403-407.

31. Y. Kitaguchi, S. Habuka, H. Okuyama, S. Hatta, T. Aruga, T. Frederiksen, M. Paulsson and H. Ueba, Sci. Rep., 2015, 5, 11796.

32. L. Herrer, A. Ismael, S. Martin, D. C. Milan, J. L. Serrano, R. J. Nichols, C. Lambert and P. Cea, Nanoscale, 2019, 11, 15871-15880.

33. X. T. Wang, T. L. R. Bennett, A. Ismael, L. A. Wilkinson, J. Hamill, A. J. P. White, I. M. Grace, O. V. Kolosov, T. Albrecht, B. J. Robinson, N. J. Long, L. F. Cohen and C. J. Lambert, J. Am. Chem. Soc., 2020, 142, 8555-8560.

34. R. Miao, H. Xu, M. Skripnik, L. Cui, K. Wang, K. G. L. Pedersen, M. Leijnse, F. Pauly, K. Warnmark, E. Meyhofer, P. Reddy and H. Linke, Nano Lett., 2018, 18, 5666-5672.

35. Z. T. Xie, I. Baldea, A. T. Demissie, C. E. Smith, Y. F. Wu, G. Haugstad and C. D. Frisbie, J. Am. Chem. Soc., 2017, 139, 5696-5699.

36. L. M. Ballesteros, S. Martín, S. Marqués-González, M. C. López, S. J. Higgins, R. J. Nichols, P. J. Low and P. Cea, J. Phys. Chem. C, 2014, 119, 784-793.

37. E. Escorihuela, P. Cea, S. Bock, D. C. Milan, S. Naghibi, H. M. Osorio, R. J. Nichols, P. J. Low and S. Martin, J. Mater. Chem. C, 2020, 8, 672-682.

38. H. M. Osorio, S. Martin, M. C. Lopez, S. Marques-Gonzalez, S. J. Higgins, R. J. Nichols, P. J. Low and P. Cea, Beilstein J. Nanotech., 2015, 6, 1145-1157.

39. L. Herrer, A. Gonzalez-Orive, S. Marques-Gonzalez, S. Martin, R. J. Nichols, J. L. Serrano, P. J. Low and P. Cea, Nanoscale, 2019, 11, 7976-7985.

40. G. Pera, S. Martin, L. M. Ballesteros, A. J. Hope, P. J. Low, R. J. Nichols and P. Cea, Chem. Eur. J., 2010, 16, 13398-13405.

41. L. M. Ballesteros, S. Martin, C. Momblona, S. Marques-Gonzalez, M. C. Lopez, R. J. Nichols, P. J. Low and P. Cea, J. Phys. Chem. C, 2012, 116, 9142-9150.

42. L. M. Ballesteros, S. Martin, G. Pera, P. A. Schauer, N. J. Kay, M. C. Lopez, P. J. Low, R. J. Nichols and P. Cea, Langmuir, 2011, 27, 3600-3610.

43. T. A. Su, M. Neupane, M. L. Steigerwald, L. Venkataraman and C. Nuckolls, Nat. Rev. Mater., 2016, 1, 1-15.

44. J. Hihath and N. J. Tao, Semicond. Sci. Tech, 2014, 29, 054007.

45. L. Herrer, S. Martín Solans, A. Gonzalez-Orive, D. Costa-Milan, A. Vezzoli, R. J. Nichols, J. L. Serrano and P. Cea, J Mater Chem C, 2021, 9, 2882 - 2889.

46. L. Luo, A. Benameur, P. Brignou, S. H. Choi, S. Rigaut and C. D. Frisbie, J. Phys. Chem. C, 2011, 115, 19955-19961.

47. S. H. Choi, C. Risko, M. C. R. Delgado, B. Kim, J. L. Bredas and C. D. Frisbie, J. Am. Chem. Soc., 2010, 132, 4358-4368.

48. D. J. Wold, R. Haag, M. A. Rampi and C. D. Frisbie, J. Phys. Chem. B, 2002, 106, 2813-2816.

49. L. J. O'Driscoll, X. T. Wang, M. Jay, A. S. Batsanov, H. Sadeghi, C. J. Lambert, B. J. Robinson and M. R. Bryce, Angew. Chem. Int. Ed., 2020, 59, 882-889.

50. T. W. Kelley, E. L. Granstrom and C. Daniel Frisbie, Adv. Mater., 1999, 11, 261-264.

51. J. M. Mativetsky, Y.-L. Loo and P. Samorì, J. Mater. Chem. C, 2014, 2, 3118-3128.

52. H. Song, H. Lee and T. Lee, J. Am. Chem. Soc, 2007, 129, 3806-3807.

53. K. Slowinski, R. V. Chamberlain, C. J. Miller and M. Majda, J. Am. Chem. Soc., 1997, 119, 11910-11919. 
54. H. Song, H. Lee and T. Lee, Ultramicroscopy, 2008, 108, 1196-1199.

55. M. Paradinas, C. Munuera, M. Buck and C. Ocal, J. Phys. Chem. B, 2018, 122, 657-665.

56. Z. Wei, X. Wang, A. Borges, M. Santella, T. Li, J. K. Sorensen, M. Vanin, W. Hu, Y. Liu, J. Ulstrup, G. C. Solomon, Q. Chi, T. Bjornholm, K. Norgaard and B. W. Laursen, Langmuir, 2014, 30, 14868-14876.

57. G. Jayamurugan, V. Gowri, D. Hernandez, S. Martin, A. Gonzalez-Orive, C. Dengiz, O. Dumele, F. Perez-Murano, J. P. Gisselbrecht, C. Boudon, W. B. Schweizer, B. Breiten, A. D. Finke, G. Jeschke, B. Bernet, L. Ruhlmann, P. Cea and F. Diederich, Chem. Eur. J., 2016, 22, 1053910547.

58. L. Herrer, V. Sebastian, S. Martin, A. Gonzalez-Orive, F. Perez-Murano, P. J. Low, J. L. Serrano, J. Santamaria and P. Cea, Nanoscale, 2017, 9, 13281-13290.

59. H. M. Osorio, P. Cea, L. M. Ballesteros, I. Gascon, S. Marques-Gonzalez, R. J. Nichols, F. PerezMurano, P. J. Low and S. Martin, J. Mater. Chem. C, 2014, 2, 7348-7355.

60. S. Martin, G. Pera, L. M. Ballesteros, A. J. Hope, S. Marques-Gonzalez, P. J. Low, F. PerezMurano, R. J. Nichols and P. Cea, Chem. Eur. J., 2014, 20, 3421-3426.

61. Z. A. Lamport, A. D. Broadnax, B. Scharmann, R. W. Bradford, A. Delacourt, N. Meyer, H. Li, S. M. Geyer, T. Thonhauser, M. E. Welker and O. D. Jurchescu, ACS Appl. Mater. Interfaces, 2019, 11, 18564-18570.

62. J. C. Lacroix, Curr. Opin. Electrochem., 2018, 7, 153-160.

63. G. Ricœur, S. Lenfant, D. Guérin and D. Vuillaume, J. Phys. Chem. C, 2012, 116, 20722-20730.

64. R. C. Chiechi, E. A. Weiss, M. D. Dickey and G. M. Whitesides, Angew. Chem. Int. Ed., 2008, 47, 142-144.

65. M. Souto, L. Yuan, D. C. Morales, L. Jiang, I. Ratera, C. A. Nijhuis and J. Veciana, J. Am. Chem. Soc., 2017, 139, 4262-4265.

66. M. Souto, V. Díez-Cabanes, L. Yuan, A. R. Kyvik, I. Ratera, C. A. Nijhuis, J. Cornil and J. Veciana, Phys. Chem. Chem. Phys., 2018, 20, 25638-25647.

67. D. Gutierrez, J. A. de Sousa, M. Mas-Torrent and N. Crivillers, ACS Appl. Electron. Mater., 2020, 2, 3093-3099.

68. F. Von Wrochem, D. Gao, F. Scholz, H. G. Nothofer, G. Nelles and J. M. Wessels, Nat. Nanotechnol., 2010, 5, 618-624.

69. N. Gemma, K. Mizushima, A. Miura and M. Azuma, Synth. Met., 1987, 18, 809-814.

70. S. Sha, T. Hisatsune, T. Moriizumi, K. Ogawa, H. Tamura, N. Mino, Y. Okahata and K. Ariga, Thin Solid Films, 1989, 179, 277-282.

71. K. S. Wimbush, R. M. Fratila, D. Wang, D. Qi, C. Liang, L. Yuan, N. Yakovlev, K. P. Loh, D. N. Reinhoudt, A. H. Velders and C. A. Nijhuis, Nanoscale, 2014, 6, 11246-11258.

72. A. Wan, L. Jiang, C. S. S. Sangeeth and C. A. Nijhuis, Adv. Funct. Mater., 2014, 24, 4442-4456.

73. C. A. Nijhuis, W. F. Reus and G. M. Whitesides, J. Am. Chem. Soc., 2010, 132, 18386-18401.

74. S. E. Byeon, M. Kim and H. J. Yoon, ACS Appl. Mater. Interfaces, 2017, 9, 40556-40563.

75. C. A. Nijhuis, W. F. Reus, J. R. Barber and G. M. Whitesides, J. Phys. Chem. C, 2012, 116, 14139-14150.

76. S. Park and H. J. Yoon, Nano Lett., 2018, 18, 7715-7718.

77. S. K. Karuppannan, H. Hongting, C. Troadec, A. Vilan and C. A. Nijhuis, Adv. Funct. Mater., 2019, 29, 1-15.

78. P. Rothemund, C. Morris Bowers, Z. Suo and G. M. Whitesides, Chem. Mater., 2018, 30, 129137.

79. S. Park and H. J. Yoon, Nano Lett., 2018, 18, 7715-7718.

80. J. Chen, T. J. Giroux, Y. Nguyen, A. A. Kadoma, B. S. Chang, B. VanVeller and M. M. Thuo, Phys. Chem. Chem. Phys., 2018, 20, 4864-4878.

81. J. Chen, S. Kundu, C. Du, A. Kadoma, T. Giroux and M. Thuo, ECS Transactions, 2018, 86, 79.

82. P. Song, S. Guerin, S. J. R. Tan, H. V. Annadata, X. Yu, M. Scully, Y. M. Han, M. Roemer, K. P. Loh, D. Thompson and C. A. Nijhuis, Adv. Mater., 2018, 30, 1-8. 
83. W. Du, T. Wang, H. S. Chu, L. Wu, R. Liu, S. Sun, W. K. Phua, L. Wang, N. Tomczak and C. A. Nijhuis, Nat. Photonics, 2016, 10, 274-280.

84. W. F. Reus, M. M. Thuo, N. D. Shapiro, C. A. Nijhuis and G. M. Whitesides, ACS Nano, 2012, 6, 4806-4822.

85. X. P. Chen, M. Roemer, L. Yuan, W. Du, D. Thompson, E. del Barco and C. A. Nijhuis, Nat. Nanotechnol., 2017, 12, 797-803.

86. Y. Han, C. Nickle, Z. Zhang, H. P. Astier, T. J. Duffin, D. Qi, Z. Wang, E. Del Barco, D. Thompson and C. A. Nijhuis, Nat. Mater., 2020, 19, 843-848.

87. M.-C. Daniel and D. Astruc, Chem. Rev., 2004, 104, 293-346.

88. E. Pensa, E. Cortes, G. Corthey, P. Carro, C. Vericat, M. H. Fonticelli, G. Benitez, A. A. Rubert and R. C. Salvarezza, Acc. Chem. Res., 2012, 45, 1183-1192.

89. H. Hakkinen, Nat. Chem., 2012, 4, 443-455.

90. D. Fracasso, S. Kumar, P. Rudolf and R. C. Chiechi, RSC Adv., 2014, 4, 56026-56030.

91. P. Maity, S. Takano, S. Yamazoe, T. Wakabayashi and T. Tsukuda, J. Am. Chem. Soc., 2013, 135, 9450-9457.

92. A. Moneo, A. González-Orive, S. Bock, M. Fenero, I. L. Herrer, D. C. Milan, M. Lorenzoni, R. J. Nichols, P. Cea, F. Perez-Murano, P. J. Low and S. Martin, Nanoscale, 2018, 10, 14128-14138.

93. S. Seo, B. Q. Viet, E. Hwang, Y. Cho, J. Lee, Y. Kawazoe and H. Lee, Small, 2019, 15, 1901183.

94. L. M. Ballesteros, S. Martin, J. Cortes, S. Marques-Gonzalez, F. Perez-Murano, R. J. Nichols, P. J. Low and P. Cea, Adv. Mater. Interfaces, 2014, 1, 1400128.

95. R. Ezquerra, S. G. Eaves, S. Bock, B. W. Skelton, F. Perez-Murano, P. Cea, S. Martin and P. J. Low, J. Mater. Chem. C, 2019, 7, 6630-6640.

96. S. Martin, L. M. Ballesteros, A. Gonzalez-Orive, H. Oliva, S. Marques-Gonzalez, M. Lorenzoni, R. J. Nichols, F. Perez-Murano, P. J. Low and P. Cea, J. Mater. Chem. C, 2016, 4, 9036-9043.

97. R. Maoz, E. Frydman, S. R. Cohen and J. Sagiv, Adv. Mater., 2000, 12, 424-429.

98. R. Maoz, S. R. Cohen and J. Sagiv, Adv. Mater., 1999, 11, 55-61.

99. S. Hoeppener, R. Maoz, S. R. Cohen, L. F. Chi, H. Fuchs and J. Sagiv, Adv. Mater., 2002, 14, 1036-1041.

100. R. Maoz, E. Frydman, S. R. Cohen and J. Sagiv, Adv. Mater., 2000, 12, 725-731.

101. L. Herrer, V. Sebastian, S. Martín, A. González-Orive, F. Pérez-Murano, P. J. Low, J. L. Serrano, J. Santamaría and P. Cea, Nanoscale, 2017, 9, 13281-13290.

102. V. Sebastian, C. D. Smith and K. F. Jensen, Nanoscale, 2016, 8, 7534-7543.

103. X. Huang, S. Tang, X. Mu, Y. Dai, G. Chen, Z. Zhou, F. Ruan, Z. Yang and N. Zheng, Nat. Nanotechnol., 2011, 6, 28-32.

104. G. Puebla-Hellmann, K. Venkatesan, M. Mayor and E. Lortscher, Nature, 2018, 559, 232-235.

105. S. Lee, J. Park, R. Ragan, S. Kim, Z. Lee, D. K. Lim, D. A. A. Ohlberg and R. S. Williams, J. Am. Chem. Soc., 2006, 128, 5745-5750.

106. J. M. Beebe, V. B. Engelkes, L. L. Miller and C. D. Frisbie, J. Am. Chem. Soc., 2002, 124, 1126811269.

107. A. V. Walker, T. B. Tighe, J. Stapleton, B. C. Haynie, S. Upilli, D. L. Allara and N. Winograd, Appl. Phys. Lett., 2004, 84, 4008-4010.

108. G. Nagy and A. V. Walker, J. Phys. Chem. C, 2007, 111, 8543-8556.

109. G. L. Fisher, A. E. Hooper, R. L. Opila, D. L. Allara and N. Winograd, J. Phys. Chem. B, 2000, 104, 3267-3273.

110. A. Hooper, G. L. Fisher, K. Konstadinidis, D. Jung, H. Nguyen, R. Opila, R. W. Collins, N. Winograd and D. L. Allara, J. Am. Chem. Soc., 1999, 121, 8052-8064.

111. G. Nagy and A. V. Walker, J. Phys. Chem. B, 2006, 110, 12543-12554.

112. G. L. Fisher, A. Hooper, R. L. Opila, D. R. Jung, D. L. Allara and N. Winograd, J. Electron. Spectrosc., 1999, 98, 139-148.

113. A. V. Walker, T. B. Tighe, B. C. Haynie, S. Uppili, N. Winograd and D. L. Allara, J. Phys. Chem. $B, 2005,109,11263-11272$. 
114. E. Polymeropoulos and J. Sagiv, J. Chem. Phys., 1978, 69, 1836-1847.

115. H. Haick, O. Niitsoo, J. Ghabboun and D. Cahen, J. Phys. Chem. C, 2007, 111, 2318-2329.

116. R. M. Metzger, T. Xu and I. R. Peterson, J. Phys. Chem. B, 2001, 105, 7280-7290.

117. T. Xu, I. R. Peterson, M. V. Lakshmikantham and R. M. Metzger, Angew. Chem. Int. Ed., 2001, 40, 1749-1752.

118. K. L. Choy, Prog. Mater. Sci., 2003, 48, 57-170.

119. P. Wohlfart, J. Weiß, J. Käshammer, M. Kreiter, C. Winter, R. Fischer and S. Mittler-Neher, Chem. Vap. Depos., 1999, 5, 165-170.

120. P. Lu, K. Demirkan, R. L. Opila and A. V. Walker, J. Phys. Chem. C, 2008, 112, 2091-2098.

121. C. Winter, U. Weckenmann, R. A. Fischer, J. Käshammer, V. Scheumann and S. Mittler, Chem. Vap. Depos., 2000, 6, 199-205.

122. Z. Shi, P. Lu and A. V. Walker, Langmuir, 2012, 28, 16909-16916.

123. P. A. Van Hal, E. C. P. Smits, T. C. T. Geuns, H. B. Akkerman, B. C. De Brito, S. Perissinotto, G. Lanzani, A. J. Kronemeijer, V. Geskin, J. Cornil, P. W. M. Blom, B. De Boer and D. M. De Leeuw, Nat. Nanotechnol., 2008, 3, 749-754.

124. A. B. Neuhausen, A. Hosseini, J. A. Sulpizio, C. E. D. Chidsey and D. Goldhaber-Gordon, ACS Nano, 2012, 6, 9920-9931.

125. F. Milani, C. Grave, V. Ferri, P. Samorì and M. A. Rampi, ChemPhysChem, 2007, 8, 515-518.

126. H. B. Akkerman and B. de Boer, J. Phys. Condens. Matter, 2007, 20, 013001.

127. G. Wang, H. Yoo, S.-I. Na, T.-W. Kim, B. Cho, D.-Y. Kim and T. Lee, Thin Solid Films, 2009, 518, 824-828.

128. A. M. Nardes, M. Kemerink and R. A. J. Janssen, Phys. Rev. B., 2007, 76, 085208.

129. G. Wang, Y. Kim, M. Choe, T.-W. Kim and T. Lee, Adv. Mater., 2011, 23, 755-760.

130. T. Li, J. R. Hauptmann, Z. Wei, S. Petersen, N. Bovet, T. Vosch, J. Nygård, W. Hu, Y. Liu, T. Bjørnholm, K. Nørgaard and B. W. Laursen, Adv. Mater., 2012, 24, 1333-1339.

131. J. Koo, Y. Jang, L. Martin, D. Kim, H. Jeong, K. Kang, W. Lee, J. Kim, W.-T. Hwang, D. Xiang, E. Scheer, M. Kabdulov, T. Huhn, F. Pauly and T. Lee, ACS Appl. Mater. Interfaces, 2019, 11, 11645-11653.

132. D. Kim, H. Jeong, W.-T. Hwang, Y. Jang, D. Sysoiev, E. Scheer, T. Huhn, M. Min, H. Lee and T. Lee, Adv. Funct. Mater., 2015, 25, 5918-5923.

133. S. Seo, M. Min, J. Lee, T. Lee, S.-Y. Choi and H. Lee, Angew. Chem. Int. Ed., 2012, 51, 108-112.

134. J. He, B. Chen, A. K. Flatt, J. J. Stephenson, C. D. Doyle and J. M. Tour, Nat. Mater., 2006, 5, 63-68.

135. R. Kumar, H. Yan, R. L. McCreery and A. J. Bergren, Phys. Chem. Chem. Phys., 2011, 13, 14318-14324.

136. A. Morteza Najarian, B. Szeto, U. M. Tefashe and R. L. McCreery, ACS Nano, 2016, 10, 89188928.

137. A. M. Najarian, A. Bayat and R. L. McCreery, J. Am. Chem. Soc., 2018, 140, 1900-1909.

138. S. Sangiao, S. Martín, A. González-Orive, C. Magén, P. J. Low, J. M. De Teresa and P. Cea, Small, 2017, 13, 1603207.

139. S. K. Karuppannan, E. H. L. Neoh, A. Vilan and C. A. Nijhuis, J. Am. Chem. Soc., 2020, 142, 3513-3524.

140. A. M. Najarian, M. Supur and R. L. McCreery, J. Phys. Chem. C, 2020, 124, 1739-1748.

141. A. P. Bonifas and R. L. McCreery, Nat. Nanotechnol., 2010, 5, 612-617.

142. S. M. George, Chem. Rev., 2010, 110, 111-131.

143. K. J. Park and G. N. Parsons, J. Vac. Sci. Technol. A, 2012, 30, 01 A162.

144. J. Z. Wu, J. Acharya and R. Goul, J. Vac. Sci. Technol. A, 2020, 38, 040802.

145. O. Seitz, M. Dai, F. S. Aguirre-Tostado, R. M. Wallace and Y. J. Chabal, J. Am. Chem. Soc., 2009, 131, 18159-18167.

146. A. C. Dürr, F. Schreiber, M. Kelsch, H. D. Carstanjen and H. Dosch, Adv. Mater., 2002, 14, $961-$ 963. 
147. C. Silien and M. Buck, J. Phys. Chem. C, 2008, 112, 3881-3890.

148. R. T. W. Popoff, A. A. Zavareh, K. L. Kavanagh and H.-Z. Yu, J. Phys. Chem. C, 2012, 116, 17040-17047.

149. C. Silien, D. Lahaye, M. Caffio, R. Schaub, N. R. Champness and M. Buck, Langmuir, 2011, 27, 2567-2574.

150. G. Pattanaik, W. Shao, N. Swami and G. Zangari, Langmuir, 2009, 25, 5031-5038.

151. Y.-D. Chiu, W.-P. Dow, K. Krug, Y.-F. Liu, Y.-L. Lee and S.-L. Yau, Langmuir, 2012, 28, 1447614487.

152. C. D. Zangmeister and R. D. van Zee, Langmuir, 2003, 19, 8065-8068.

153. P. Lu and A. V. Walker, Langmuir, 2007, 23, 12577-12582.

154. P. Lu, Z. Shi and A. V. Walker, Langmuir, 2011, 27, 13022-13028.

155. D. Aldakov, Y. Bonnassieux, B. Geffroy and S. Palacin, ACS Appl. Mater. Interfaces, 2009, 1, 584-589.

156. L. Lacourcelle, Traité de galvanotechnique, Galva-Conseils édition, 1996.

157. W. J. Dressick, C. S. Dulcey, J. H. Georger and J. M. Calvert, Chem. Mater., 1993, 5, 148-150.

158. J. C. Garno, C. D. Zangmeister and J. D. Batteas, Langmuir, 2007, 23, 7874-7879.

159. D. Zabetakis and W. J. Dressick, ACS Appl. Mater. Interfaces, 2009, 1, 4-25.

160. J. C. Love, L. A. Estroff, J. K. Kriebel, R. G. Nuzzo and G. M. Whitesides, Chem. Rev., 2005, 105, 1103-1170.

161. Z. Shi and A. V. Walker, Langmuir, 2011, 27, 11292-11295.

162. Y.-L. Loo, D. V. Lang, J. A. Rogers and J. W. P. Hsu, Nano Lett., 2003, 3, 913-917.

163. J. R. Niskala, W. C. Rice, R. C. Bruce, T. J. Merkel, F. Tsui and W. You, J. Am. Chem. Soc., 2012, 134, 12072-12082.

164. D. Guerin, C. Merckling, S. Lenfant, X. Wallart, S. Pleutin and D. Vuillaume, J. Phys. Chem. C, 2007, 111, 7947-7956.

165. R. C. Bruce, R. Wang, J. Rawson, M. J. Therien and W. You, J. Am. Chem. Soc., 2016, 138, 2078-2081.

166. Y.-L. Loo, R. L. Willett, K. W. Baldwin and J. A. Rogers, J. Am. Chem. Soc., 2002, 124, 76547655.

167. J. W. P. Hsu, Materials Today, 2005, 8, 42-54.

168. A. Vilan and D. Cahen, Adv. Funct. Mater., 2002, 12, 795-807.

169. A. Vilan, A. Shanzer and D. Cahen, Nature, 2000, 404, 166-168.

170. Y. Selzer and D. Cahen, Adv. Mater., 2001, 13, 508-511.

171. A. Salomon, D. Berkovich and D. Cahen, Appl. Phys. Lett., 2003, 82, 1051-1053.

172. D. Xiang, X. Wang, C. Jia, T. Lee and X. Guo, Chem. Rev., 2016, 116, 4318-4440.

173. A. Vilan, J. Ghabboun and D. Cahen, J. Phys. Chem. B, 2003, 107, 6360-6376.

174. H. Haick, M. Ambrico, T. Ligonzo, R. T. Tung and D. Cahen, J. Am. Chem. Soc., 2006, 128, 6854-6869.

175. H. Haick and D. Cahen, Acc. Chem. Res., 2008, 41, 359-366.

176. K. T. Shimizu, J. D. Fabbri, J. J. Jelincic and N. A. Melosh, Adv. Mater., 2006, 18, 1499-1504.

177. N. Stein, R. Korobko, O. Yaffe, R. Har Lavan, H. Shpaisman, E. Tirosh, A. Vilan and D. Cahen, J. Phys. Chem. C, 2010, 114, 12769-12776. 